\title{
Countercyclical Contingent Capital
}

\author{
Emilio Barucci \\ Dipartimento di Matematica - Politecnico di Milano \\ Piazza Leonardo da Vinci, 32 - 20133 Milano (Italy) \\ Luca Del Viva \\ ESADE Business School \\ Av. Pedralbes, 60-62, Barcelona, 08034, (Spain)
}

April 15, 2011

\begin{abstract}
We analyze the optimal capital structure of a bank issuing countercyclical contingent capital, i.e., notes to be converted in common shares in case of a bad state for the economy. This type of asset reduces the spread of straight debt but is quite expensive. The effect on bankruptcy costs is limited (it is strong when contingent capital is not countercyclical), the asset reduces the asset substitution incentive. Contingent capital is useful for macroprudential regulation, the countercyclical feature is important depending on priorities (moderate the asset substitution incentive or reduce bankruptcy costs).
\end{abstract}

Keywords: Countercyclical Contingent Capital, Convertible Bonds, Capital Structure, Leverage.

JEL Code numbers: G21, G28, G32, G33. 


\section{Introduction}

The recent financial crisis has raised two new issues on the banking regulation debate: the too big to fail problem and the management of systemic risk. In this paper we analyze a hybrid instrument that has been proposed recently to address these issues: countercyclical contingent capital (CCC), a debt note to be converted in capital by a decision of the regulatory authority, see Basel Committee on Banking Supervision 2009, 2010b], Bernanke 2009, EU Commission 2010, Squam Lake Working Group [2009].

The too big to fail problem and the management of systemic risk are strictly connected to recent developments on regulation of financial markets and institutions. The liberalization of financial markets and the decentralization of controls on financial intermediation have changed significantly the financial system, in particular financial intermediaries behave more homogeneously and are strongly interconnected in a variety of regulated and unregulated markets, see Brunnermeier 2009, Haldane 2009]. These features of the financial system have played a key role in generating the recent crisis. In this environment, a failure in the evaluation of risk (by internal models of banks or by credit agencies) or an exogenous event undermining significantly the value of the assets, e.g. the fall of house prices, has caused serious drawbacks on the stability of financial institutions and of the financial system as a whole. This is the main argument against the default of large intermediaries during a financial crisis: a default of a large company would induce a negative externality on the financial system as a whole (defaults come together). Because of these externalities, the default of a large bank is no more a private event, it becomes a public issue.

In this framework there is a connection between a microeconomic event (bank default) and the macroeconomy (financial stability). This implies that we need a new governing system acting both at the micro level - via regulation - on the stability of financial institutions and at the macro level governing financial conditions.

During the financial crisis, financial authorities and the States have reacted to 
these problems using innovative non conventional instruments. To address the too big to fail problem they have injected capital in banks subscribing all kinds of financial instruments (equity, hybrid securities, debt instruments) or have guaranteed assets of financial institutions. To cope with systemic risk, central banks have acted as lenders of last resort both for banks and for States providing liquidity, buying assets of private companies or of States and lowering significantly interest rates.

Passed the peak of the crisis, a huge debate arises on building a new financial architecture capitalizing the financial crisis experience, among others see Admati and Pfleiderer 2009, Duffie 2009, Flannery 2009, Hart and Zingales 2009, Hellwig [2010], Kashyap et al. 2008, Squam Lake Working Group 2009. Recently the Basel committee on banking supervision has started to address these problems formulating some proposals, see Basel Committee on Banking Supervision 2009, 2010a b], and strengthening capital requirements of banks (higher ratios and quality of capital, liquidity and leverage ratios), see Basel Committee on Banking Supervision 2010c].

In this perspective, regulatory authorities have referred to contingent capital - debt instruments to be converted into equity when a predefined event occurs, see Basel Committee on Banking Supervision 2009, 2010b, Bernanke 2009, EU Commission [2010]. In particular this asset seems to be well suited to address the regulation of systemic important financial institutions.

Several types of hybrid securities have been proposed, see Barucci and Del Viva | 2010], Flannery 2002, 2009, McDonald 2010], Pennacchi et al. 2010, Raviv [2004], Squam Lake Working Group 2009], Sundaresan and Wang 2010]. Flannery [2002, 2009 propose mandatory subordinated convertible bonds (contingent capital certificates): notes are converted automatically into common stocks at the current share price if the issuing firm's capital ratio (or an accounting ratio) falls below some pre-specified level. Conversion is triggered automatically by the stock price and the value of the company. Such an instrument has been employed during the financial crisis by Lloyd's Bank. Raviv 2004 analyses a zero-coupon debt for equity swap that converts automatically into equity if the corporate value falls below a predetermined 
threshold. In Barucci and Del Viva 2010] we have studied the optimal capital structure of a company issuing perpetual notes that may be converted in common shares by a company decision or by an automatic rule. Squam Lake Working Group [2009] proposes an instrument similar to that of Flannery [2009] with the difference that bonds are converted in equity if two conditions are met (declaration by the systemic regulator of a crisis status and low capital ratio). As in De Martino et al. [2010], we call this instrument countercyclical contingent capital or certificate (CCC). McDonald [2010 explicitly models the systemic component assuming that conversion is triggered by an exogenous barrier on the equity price and on a financial index.

In this paper we investigate the capital structure of a bank issuing straight debt (deposit) and CCC using contingent claim analysis in the spirit of Merton [1977], Crouhy and Galai [1991]. The main novelty with respect to the literature is the countercyclical feature of the instrument that is analyzed in the Hackbarth et al. 2006 framework: regulatory authority imposes conversion in a crisis period. We show that the bank issuing also CCC becomes slightly more leveraged, large part of the risk is absorbed by CCC holders (CCC spread is high and that of straight debt is significantly smaller than in a standard setting), CCC reduces the asset substitution incentive while bankruptcy costs are reduced only by issuing non countercyclical contingent capital (conversion doesn't depend on the macroeconomic state). So the main policy implication of our analysis is that CCC is an useful instrument for macroprudential regulation, the countercyclical feature may be useful depending on priorities (reduce bankruptcy costs or the asset substitution incentive). Countercyclical (or not) contingent capital is superior to a debt restructuring forced by the regulatory authority in a bad state. To reduce the cost of bankruptcy, conversion of CCC in equity should occur for a high threshold (early enough).

The effects produced by the issue of CCC are similar to those produced by the prompt corrective action (PCA) by the FDIC documented in Episcopos [2008] and Aggarwal and Jacques 2001]. In particular the presence of CCC in the capital structure could concur in reducing the bankruptcy cost and the asset substitution incentive. 
Tighter conversion rules, in term of higher trigger barrier, reinforce these main results as in Episcopos 2008.

To our knowledge this is the first paper that fully determines the optimal capital structure with countercyclical contingent capital. Compared to Albul et al. [2010] we add the countercyclicality feature, we optimally chose the capital structure and we analyze the effect of macroeconomic conditions. In Pennacchi 2010 and Pennacchi et al. 2010 two different kinds of contingent convertibles are analyzed when the asset dynamic allows for jumps. Our work differs from these papers because in our setting jumps are defined as a regime switch for macroeconomic conditions, moreover we fully determine the optimal capital structure of the bank. The main novelty with respect to the literature is that we determine the remuneration of default and of the write down risk when coupons are chosen optimally.

The paper is organized as follows. In Section 2 we introduce the model for the operating profit and the CCC instrument. In Section 3 and 4 we address the evaluation of financial instruments of the company in a two period setting assuming that the bank issues straight debt and CCCs and convert them marking the start of Period 1. In Section 5 we address the optimal capital structure problem in a good macroeconomic state. In Section 6 we provide some comparative static exercises. In Section 7 we analyze the asset substitution problem when the bank may also issue contingent capital. In Section 8 we concentrate on the capital structure when the economy is in a bad state. In Section 9 we analyze the case of pure contingent capital (non countercyclical). In Section 10 we consider a multiperiod setting with a countercyclical callable bond. Finally in Section 11 we analyze the effect of CCC on bankruptcy costs. 


\section{Countercyclical contingent capital in a switching regime setting}

We analyze the capital structure of a company issuing countercyclical contingent certificates when the instantaneous operating profit $(E B I T)$ is affected by macroeconomic conditions. We follow Hackbarth et al. 2006 assuming that at time $t$ the EBIT for the bank is

$$
f(x(t), y(t))=x(t) y(t)
$$

where

$$
d x(t)=\mu x(t) d t+\sigma x(t) d W(t), \quad x(0)>0
$$

represents the idiosyncratic component of the EBIT. The growth rate $\mu<r$ and the volatility $\sigma>0$ are constant parameters and $d W(t)$ is the increment of a standard Brownian motion. Throughout the paper $r$ represents the constant risk-free interest rate. $y(t)$ instead is a random variable that consists in persistent EBIT jumps reflecting macroeconomic conditions. $y(t)$ may assume only two states: $y_{H}$ and $y_{L}\left(y_{H}>y_{L}\right)$, where $y_{H}$ represents a positive macroeconomic condition (GDP higher than past average, Bank Index above some level) and $y_{L}$ represents a bad macroeconomic condition (onset of a crisis for example).

$y(t)$ follows a Poisson process independent from $d W(t)$ with transition probability law

- $\lambda_{L}=$ rate of leaving state $\mathrm{L}$ for state $\mathrm{H}$

- $\lambda_{H}=$ rate of leaving state $\mathrm{H}$ for state $\mathrm{L}$.

So basically if macroeconomic conditions are sound, for an infinitesimal time interval $d t$ we have approximately a probability $\lambda_{H} d t$ of the onset of a crisis. If the crisis starts, then the EBIT will jump at the level $x\left(t_{+}\right)=x\left(t_{-}\right) y_{L}$, where $x\left(t_{-}\right)$represents the EBIT an instant before the jump. Given the interpretation of $y(t)$ we assume that $y_{L} \leq 1 \leq y_{H}$. 
A CCC is a debt instrument that behaves in a different way depending on the state of the economy. If macroeconomic conditions are good, i.e., $y(t)=y_{H}$, then equity holders can decide to go bankrupt without converting CCCs. On the other hand, if macroeconomic conditions are bad (crisis or deep depression), i.e., $y(t)=y_{L}$, and the operating profit is not high enough then CCCs are converted in equity without incurring in bankruptcy. For the moment we assume that after the conversion of CCCs the bank may default as a normal company, i.e., the decision is only in the hands of equity holders. This assumption will be relaxed in Section 10 when we will introduce the possibility of dynamic debt restructuring. While the bankruptcy decision in a good state is a pure private decision, the conversion decision of CCCs in a bad state is imposed by the regulatory authority. CCC cannot be converted in a good or in a bad state of the economy by an autonomous decision of equity holders. In this framework CCCs will be converted only if the bank is performing bad and the authority recognizes the existence of a global crisis. We assume that the regulatory authority fully observes the process $y(t)$, that is the regulatory authority is able to detect a state of crisis disentangling the evolution of $x(t)$ and that of $y(t)$ : the crisis condition is determined by the state $y_{L}$ and the conversion is triggered by a barrier on $x(t)$.

As in Barucci and Del Viva 2010 we start considering a two period framework. Period 1 starts as CCCs are converted into equity. After conversion the capital structure of the bank is composed solely by equity and straight debt (deposits). As in Hackbarth et al. 2006], in Period 1 the bank defaults in both macroeconomic states ( $H$ and $L$ ) as the cash flow from operations reaches respectively the barrier $x_{H_{1}}^{*}$ or $x_{L_{1}}^{*}$. These default barriers are optimally chosen by equity holders. In Section 10 we will consider the possibility that the bank issues again CCCs after their conversion.

In Period 0 the bank has the possibility to issue CCCs, along with equity and deposits (straight debt), that can be converted into equity if macroeconomic conditions are bad and the cash flow reaches a lower barrier $x_{L_{0}}^{*}$, see Table 1. In these circumstances the bank doesn't default, a fraction of equity is allocated to CCC holders and depositors do not bear any loss. The contract of contingent capital is such that at con- 


\section{Period 1}

$$
\begin{array}{lll}
\text { if } \quad y(t)=y_{L} \quad \text { and } & x_{L}(t) \leq x_{L_{1}}^{*} \quad \rightarrow \text { default } \\
\text { if } \quad y(t)=y_{H} \quad \text { and } \quad x_{H}(t) \leq x_{H_{1}}^{*} \quad \rightarrow \text { default }
\end{array}
$$

\section{Period 0}

$$
\begin{array}{ll}
\text { if } \quad y(t)=y_{L} \quad \text { and } \quad x_{L}(t) \leq x_{L_{0}}^{*} \quad \rightarrow \text { conversion } \\
\text { if } \quad y(t)=y_{H} \quad \text { and } \quad x_{H}(t) \leq x_{H_{0}}^{*} \quad \rightarrow \text { default }
\end{array}
$$

Table 1: Default-conversion dynamics.

version, CCC holders obtain a portion of equity equal to their par value or otherwise, if equity results to be lower than the par value of CCCs, they will take over completely the company, i.e., they will receive the full value of equity.

Set $e_{L_{1}}\left(x_{L_{0}}^{*}\right)$ the equity value after conversion in Period 1 at the conversion barrier $x_{L_{0}}^{*}$ and assuming that CCCs pay a coupon $c c$ continuously, the conversion rate of CCCs in a bad state is

$$
\theta=\min \left\{\frac{c c / r}{e_{L_{1}}\left(x_{L_{0}}^{*}\right)}, 1\right\} .
$$

A $\theta$ equals to 1 means that contingent capital holders replace completely old equity holders in case of conversion. In this case CCC holders indeed suffer a loss because the par value of bonds is higher than the equity value $\left(\frac{c c / r}{e_{L_{1}}\left(x_{L_{0}}^{*}\right)}>1\right)$. Conversion in these circumstances produces an effect similar to bankruptcy-restructuring: depositors continue to possess the right for a fixed stream, equity holders are ejected from the company and CCC holders will obtain the residual claim. For a discussion on the conversion mechanism see Barucci and Del Viva [2010, Pennacchi 2010].

If macroeconomic conditions are good and the lower barrier $x_{H_{0}}^{*}$ is touched, then the bank defaults, CCC holders and depositors obtain a fraction of the net abandonment value, and equity holders obtain the residual value. $x_{H_{0}}^{*}$ is chosen by equity holders.

Figure 1 provides a graphical illustration of the default and conversion dynamics. We assume $x_{L_{i}}^{*}>x_{H_{i}}^{*}$ in both periods (0 and 1), i.e., the bank defaults in recession earlier than in expansion. An assumption that is confirmed by optimal decisions in 


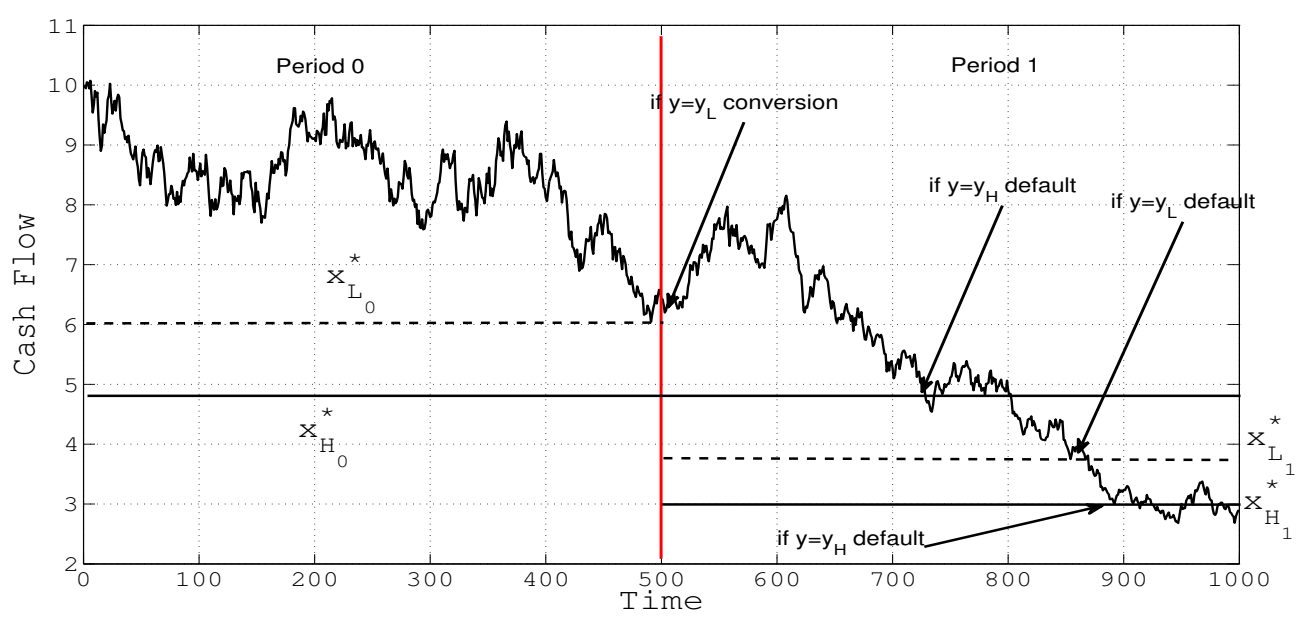

Figure 1: Conversion-default dynamics. The red line divides period 0 where CCCs, straight debt and equity are contemporaneously present in the capital structure, from period 1 , where after conversion only straight debt and equity are present.

Period 1. In order to avoid a too late conversion (a conversion that leads immediately to default after conversion), we assume that $x_{L_{0}}^{*}>x_{L_{1}}^{*}$. This assumption avoids the trivial situation in which the conversion of $\mathrm{CCCs}$, ordered by the financial authority in order to avoid bankruptcy, will actually lead to the default after conversion.

\section{Period 1 analysis}

After the conversion of CCCs in equity, the company becomes a leveraged company as in Hackbarth et al. 2006]. There are only two claimants: shareholders and straight debtholders. There are also two other occult claimants: bankruptcy and government (via taxes).

As a preliminary step to evaluate the value of financial assets we have to compute the abandonment value $A_{i}, i=L, H$, i.e., the expected discounted value of the perpetual claim to the after tax flow of operating income. $A_{i}, i=L, H$, represents the after tax unlevered company value in the two different states. In case of default in state 
$i=L, H$, debtholders receive $\alpha_{i} A_{i}, i=L, H$, the fraction $1-\alpha_{i}$ of the abandonment value of the firm instead is lost because of bankruptcy costs. The expression of $A_{i}$ is similar to that computed in Hackbarth et al. 2006 and is provided in A.

Our strategy is to determine first the value of straight debt, then the total value of the company and finally the value of equity by difference. The next four subsections 3.1. 3.2, 3.3 and 3.4 summarize the main results obtained in Hackbarth et al. 2006].

\subsection{Debt Value}

We assume that debt pays a continuous constant coupon $c$ until time $T=\min \{s, \infty\}$ where $s=\min \left\{t: x(t) \leq x_{i_{1}}^{*}\right\}, i=L, H$, is the default stopping time. Debtholders receive a constant coupon equal to $c$ as long as the bank doesn't reach the lower bankruptcy barriers $x_{i_{1}}^{*}, i=L, H$.

We denote by $d_{i_{1}}(x), i=H, L$, the debt value in the two states. Debt value has to satisfy the following system of ordinary differential equations (ODEs):

- if $x_{H_{1}}^{*} \leq x \leq x_{L_{1}}^{*}$ :

$$
r d_{H_{1}}(x)=\mu x d_{H_{1}}^{\prime}(x)+\frac{\sigma^{2}}{2} x^{2} d_{H_{1}}^{\prime \prime}(x)+\lambda_{H}\left[\alpha_{L} A_{L}(x)-d_{H_{1}}(x)\right]+c
$$

- if $x>x_{L_{1}}^{*}$ :

$$
\left\{\begin{array}{l}
r d_{L_{1}}(x)=\mu x d_{L_{1}}^{\prime}(x)+\frac{\sigma^{2}}{2} x^{2} d_{L_{1}}^{\prime \prime}(x)+\lambda_{L}\left[d_{H_{1}}(x)-d_{L_{1}}(x)\right]+c \\
r d_{H_{1}}(x)=\mu x d_{H_{1}}^{\prime}(x)+\frac{\sigma^{2}}{2} x^{2} d_{H_{1}}^{\prime \prime}(x)+\lambda_{H}\left[d_{L_{1}}(x)-d_{H_{1}}(x)\right]+c
\end{array}\right.
$$

The solution of the system coincides with that reported in Hackbarth et al. 2006 without the instantaneously rolling over of debt, i.e., $m=0$ in their notation. As bankruptcy occurs, debtholders receive a fraction $\alpha_{i}$ of the abandonment value A.2):

$$
\begin{aligned}
d_{L_{1}}\left(x_{L_{1}}^{*}\right) & =\alpha_{L} A_{L}\left(x_{L_{1}}^{*}\right) \\
d_{H_{1}}\left(x_{H_{1}}^{*}\right) & =\alpha_{H} A_{H}\left(x_{H_{1}}^{*}\right) \\
\lim _{x \downarrow x_{L_{1}}^{*}} d_{H_{1}}(x, c) & =\lim _{x \uparrow x_{L_{1}}^{*}} d_{H_{1}}(x, c) \\
\lim _{x \downarrow x_{L_{1}}^{*}} d_{H_{1}}^{\prime}(x, c) & =\lim _{x \uparrow x_{L_{1}}^{*}} d_{H_{1}}^{\prime}(x, c) .
\end{aligned}
$$


Then we obtain the following formulae for debt value:

$$
\begin{gathered}
d_{L_{1}}(x)= \begin{cases}A_{d} x^{\xi}-\lambda_{L} B_{d} x^{\gamma}+\frac{c}{r}, & x>x_{L_{1}}^{*} \\
\alpha_{L}(1-\tau) K_{L} x, & x \leq x_{L_{1}}^{*}\end{cases} \\
d_{H_{1}}(x)= \begin{cases}A_{d} x^{\xi}+\lambda_{H} B_{d} x^{\gamma}+\frac{c}{r}, & x>x_{L_{1}}^{*} \\
C_{d} x^{\beta_{1}}+D_{d} x^{\beta_{2}}+\lambda_{H} \frac{(1-\tau) \alpha_{L} K_{L} x}{r-\mu+\lambda_{H}}+\frac{c}{r+\lambda_{H}}, & x_{H_{1}}^{*}<x \leq x_{L_{1}}^{*} \\
\alpha_{H}(1-\tau) K_{H} x, & x \leq x_{H_{1}}^{*}\end{cases}
\end{gathered}
$$

where

$$
\begin{aligned}
\beta_{1} & =0.5-\mu / \sigma^{2}+\sqrt{\left(0.5-\mu / \sigma^{2}\right)^{2}+2\left(r+\lambda_{H}\right) / \sigma^{2}} \\
\beta_{2} & =0.5-\mu / \sigma^{2}-\sqrt{\left(0.5-\mu / \sigma^{2}\right)^{2}+2\left(r+\lambda_{H}\right) / \sigma^{2}} \\
\gamma & =0.5-\mu / \sigma^{2}-\sqrt{\left(0.5-\mu / \sigma^{2}\right)^{2}+2\left(r+\lambda_{H}+\lambda_{L}\right) / \sigma^{2}} \\
\xi & =0.5-\mu / \sigma^{2}-\sqrt{\left(0.5-\mu / \sigma^{2}\right)^{2}+2 r / \sigma^{2}}
\end{aligned}
$$

and the constants $A_{d}, B_{d}, C_{d}$ and $D_{d}$ are reported in $\mathrm{B}$. The value of $K_{i}, i=H, L$ is given by A.3.

\subsection{Firm Value}

The total firm value in the two states $v_{i_{1}}(x), i=H, L$, is obtained summing the present value of the perpetual after tax income stream, the present value of the perpetual tax benefit of debt and subtracting bankruptcy costs. We assume that company profits are taxed at the rate $\tau$. In order to obtain the total firm value we have to solve the following system of ODEs:

- if $x_{H_{1}}^{*} \leq x \leq x_{L_{1}}^{*}$ :

$$
r v_{H_{1}}(x)=\mu x v_{H_{1}}^{\prime}(x)+\frac{\sigma^{2}}{2} x^{2} v_{H_{1}}^{\prime \prime}(x)+\lambda_{H}\left[\alpha_{L} A_{L}(x)-v_{H_{1}}(x)\right]+(1-\tau) x y_{H}+c \tau
$$

- if $x>x_{L_{1}}^{*}$ :

$$
\left\{\begin{array}{l}
r v_{L_{1}}(x)=\mu x v_{L_{1}}^{\prime}(x)+\frac{\sigma^{2}}{2} x^{2} v_{L_{1}}^{\prime \prime}(x)+\lambda_{L}\left[v_{H_{1}}(x)-v_{L_{1}}(x)\right]+(1-\tau) x y_{L}+c \tau \\
r v_{H_{1}}(x)=\mu x v_{H_{1}}^{\prime}(x)+\frac{\sigma^{2}}{2} x^{2} v_{H_{1}}^{\prime \prime}(x)+\lambda_{H}\left[v_{L_{1}}(x)-v_{H_{1}}(x)\right]+(1-\tau) x y_{H}+c \tau
\end{array}\right.
$$


with the following boundary conditions:

$$
\begin{aligned}
v_{L_{1}}\left(x_{L_{1}}^{*}\right) & =\alpha_{L} A_{L}\left(x_{L_{1}}^{*}\right) \\
v_{H_{1}}\left(x_{H_{1}}^{*}\right) & =\alpha_{H} A_{H}\left(x_{H_{1}}^{*}\right) \\
\lim _{x \uparrow x_{L_{1}}^{*}} v_{H_{1}}(x) & =\lim _{x \downarrow x_{L_{1}}^{*}} v_{H_{1}}(x) \\
\lim _{x \uparrow x_{L_{1}}^{*}} v_{H_{1}}^{\prime}(x) & =\lim _{x \downarrow x_{L_{1}}^{*}} v_{H_{1}}^{\prime}(x) .
\end{aligned}
$$

Using a notation similar to Hackbarth et al. 2006 we obtain the following results for the firm value:

$$
\begin{gathered}
v_{L_{1}}(x)= \begin{cases}A_{v} x^{\xi}-\lambda_{L} B_{v} x^{\gamma}+(1-\tau) K_{L} x+\frac{\tau c}{r}, & x>x_{L_{1}}^{*} \\
\alpha_{L}(1-\tau) K_{L} x, & x \leq x_{L_{1}}^{*}\end{cases} \\
v_{H_{1}}(x)= \begin{cases}A_{v} x^{\xi}+\lambda_{H} B_{v} x^{\gamma}+(1-\tau) K_{H} x+\frac{\tau c}{r}, & x>x_{L_{1}}^{*} \\
C_{v} x^{\beta_{1}}+D_{v} x^{\beta_{2}}+\lambda_{H} \frac{(1-\tau) \alpha_{L} K_{L} x}{r-\mu+\lambda_{H}}+\frac{(1-\tau) y_{H} x}{r-\mu+\lambda_{H}}+\frac{\tau c}{r+\lambda_{H}}, & x_{H_{1}}^{*}<x \leq x_{L_{1}}^{*} \\
\alpha_{H}(1-\tau) K_{H} x, & x \leq x_{H_{1}}^{*}\end{cases}
\end{gathered}
$$

where $\beta_{1}, \beta_{2}, \gamma$ and $\xi$ are defined in (3.3)-(3.6) and the constants $A_{v}, B_{v}, C_{v}$ and $D_{v}$ are reported in $\mathrm{B}$. The value of $K_{i}, i=H, L$ is given by A.3.

\subsection{Equity Value}

The equity value in the two states $e_{i_{1}}(x), i=H, L$, is obtained subtracting the debt value from the firm value:

$$
\begin{gathered}
e_{L_{1}}(x)= \begin{cases}v_{L_{1}}(x)-d_{L_{1}}(x), & x>x_{L_{1}}^{*} \\
0, & x \leq x_{L_{1}}^{*}\end{cases} \\
e_{H_{1}}(x)= \begin{cases}v_{H_{1}}(x)-d_{H_{1}}(x), & x>x_{L_{1}}^{*} \\
v_{H_{1}}(x)-d_{H_{1}}(x), & x_{H_{1}}^{*}<x \leq x_{L_{1}}^{*} \\
0, & x \leq x_{H_{1}}^{*} .\end{cases}
\end{gathered}
$$

Substituting the expression for the firm and the debt value we obtain

$$
e_{L_{1}}(x)= \begin{cases}A_{e} x^{\xi}-\lambda_{L} B_{e} x^{\gamma}+(1-\tau)\left(K_{L} x-\frac{c}{r}\right), & x>x_{L_{1}}^{*} \\ 0, & x \leq x_{L_{1}}^{*}\end{cases}
$$




$$
e_{H_{1}}(x)= \begin{cases}A_{e} x^{\xi}+\lambda_{H} B_{e} x^{\gamma}+(1-\tau)\left(K_{H} x-\frac{c}{r}\right), & x>x_{L_{1}}^{*} \\ C_{e} x^{\beta_{1}}+D_{e} x^{\beta_{2}}+(1-\tau)\left(\frac{x y_{H}}{r-\mu+\lambda_{H}}-\frac{c}{r+\lambda_{H}}\right), & x_{H_{1}}^{*}<x \leq x_{L_{1}}^{*} \\ 0, & x \leq x_{H_{1}}^{*}\end{cases}
$$

where $\beta_{1}, \beta_{2}, \gamma$ and $\xi$ are defined in (3.3)-(3.6) and the constants $A_{e}, B_{e}, C_{e}$ and $D_{e}$ are reported in $\mathrm{B}$. The value of $K_{i}, i=H, L$ is given by A.3.

\subsection{Default Strategy}

We assume that the default barriers in Period 1 are strategically chosen by equity holders, in particular we assume that they are determined by applying the smooth pasting conditions. This default strategy balances the present value of cash flow generated by the company with the cash flow that equity holders receive as the company defaults. Set $R \equiv x_{L_{1}}^{*} / x_{H_{1}}^{*}$ the ratio of the two barriers, continuity $\left(\lim _{x \uparrow x_{L_{1}}^{*}} e_{H_{1}}(x)=\right.$ $\left.\lim _{x \downarrow x_{L_{1}}^{*}} e_{H_{1}}(x), \lim _{x \uparrow x_{L_{1}}^{*}} e_{H_{1}}^{\prime}(x)=\lim _{x \downarrow x_{L_{1}}^{*}} e_{H_{1}}^{\prime}(x)\right)$ and smooth pasting conditions $\left(\left(e_{H_{1}}^{\prime}\left(x_{H_{1}}^{*}\right)=\right.\right.$ $0, e_{L_{1}}^{\prime}\left(x_{L_{1}}^{*}\right)=0$ ), where the derivative is taken with respect to $x$ and equity values are given in (3.7) and (3.8), yield

$$
\begin{aligned}
x_{H_{1}}^{*}= & c \frac{\frac{1}{r} \frac{\xi}{\xi-\gamma}\left(1+\frac{\lambda_{H}}{\lambda_{L}}\right)-\frac{1}{r+\lambda_{H}}\left(1+\frac{\beta_{2} R^{\beta_{1}}-\beta_{1} R^{\beta_{2}}}{\beta_{1}-\beta_{2}}\right)}{\frac{R K_{L}}{\xi-\gamma}\left(\gamma-1+(\xi-1) \frac{\lambda_{H}}{\lambda_{L}}\right)+R K_{H}-\frac{y_{H}}{r-\mu+\lambda_{H}}\left(R+\frac{\left(\beta_{2}-1\right) R^{\beta_{1}}-\left(\beta_{1}-1\right) R^{\beta_{2}}}{\beta_{1}-\beta_{2}}\right)} \\
x_{L_{1}}^{*}= & c \frac{\frac{1}{r}\left(\frac{\xi \gamma}{\xi-\gamma}+\frac{\lambda_{H} \xi \gamma}{\lambda_{L}(\xi-\gamma)}\right)-\frac{\beta_{1} \beta_{2} R^{\beta_{1}-\beta_{1} \beta_{2} R^{\beta_{2}}}}{\beta_{1}-\beta_{2}} \frac{1}{r+\lambda_{H}}}{R K_{L} \frac{\xi(\gamma-1)+\gamma(\xi-1) \frac{\lambda_{H}}{\lambda_{L}}}{\xi-\gamma}+R K_{H}-\frac{y_{H}}{r-\mu+\lambda_{H}}\left(R+\frac{\beta_{1}\left(\beta_{2}-1\right) R^{\beta_{1}}-\beta_{2}\left(\beta_{1}-1\right) R^{\beta_{2}}}{\beta_{1}-\beta_{2}}\right)} .
\end{aligned}
$$

\section{Period 0 analysis}

Before conversion of CCCs, we have three claimants (shareholders, straight debtholders, contingent capital holders) and the bankruptcy claim.

\subsection{Debt Value}

As in Period 1, the bank pays a constant coupon $c$ to depositors before conversion. If macroeconomic conditions are good and the lower barrier $x_{H_{0}}^{*}$ is touched, then the 
bank defaults and depositors obtain a fraction $\delta \in[0,1]$ of the abandonment value after bankruptcy $\left(\alpha_{H_{0}} A_{H}(x)\right)$ computed in $x_{H_{0}}^{*}$ (the fraction $1-\delta$ goes to CCC holders). To account for the difference in the capital structure, the default recovery ratio in Period $0\left(\alpha_{H_{0}}\right)$ is assumed to differ from the recovery ratio in Period $1\left(\alpha_{H}\right)$. On the other hand, if macroeconomic conditions are bad and the lower barrier $x_{L_{0}}^{*}$ is touched then CCCs are converted in equity, the bank reorganizes its capital structure and depositors obtain their claim with a value computed for Period 1. After conversion, the bank redefines the bankruptcy barrier but doesn't change the coupon of bonds. Set the debt value $d_{i_{0}}(x), i=L, H$, we have

- if $x_{H_{0}}^{*} \leq x \leq x_{L_{0}}^{*}$ :

$$
r d_{H_{0}}(x)=\mu x d_{H_{0}}^{\prime}(x)+\frac{\sigma^{2}}{2} x^{2} d_{H_{0}}^{\prime \prime}(x)+\lambda_{H}\left[d_{L_{1}}(x)-d_{H_{0}}(x)\right]+c
$$

where $d_{L_{1}}(x)$ is the debt value of Period 1 as derived in Section 3.1. The general solution of the above differential equation is

$$
d_{H_{0}}(x)=U_{1} x^{\phi_{1}}+U_{2} x^{\phi_{2}}+\lambda_{H} y_{p}(x)+\frac{c}{r+\lambda_{H}}
$$

where $\phi_{1}$ and $\phi_{2}$ are the negative and positive root of the the following quadratic equation

$$
\left(r+\lambda_{H}\right)-\left(\mu-\frac{\sigma^{2}}{2}\right) \phi-\frac{\sigma^{2}}{2} \phi^{2}=0
$$

and $y_{p}(x)$ is a particular solution of the non-homogeneous Cauchy-Euler equation

$$
y_{p}(x)=\left(\int-\frac{2 x^{-\left(1+\phi_{1}\right)} d_{L_{1}}(x)}{\left(\phi_{1}-\phi_{2}\right) \sigma^{2}} d x\right) x^{\phi_{1}}+\left(\int \frac{2 x^{-\left(1+\phi_{2}\right)} d_{L_{1}}(x)}{\left(\phi_{1}-\phi_{2}\right) \sigma^{2}} d x\right) x^{\phi_{2}}
$$

- if $x>x_{L_{0}}^{*}$ the debt value is given by the solution of the following system of ODEs:

$$
\left\{\begin{array}{l}
r d_{L_{0}}(x)=\mu x d_{L_{0}}^{\prime}(x)+\frac{\sigma^{2}}{2} x^{2} d_{L_{0}}^{\prime \prime}(x)+\lambda_{L}\left[d_{H_{0}}(x)-d_{L_{0}}(x)\right]+c \\
r d_{H_{0}}(x)=\mu x d_{H_{0}}^{\prime}(x)+\frac{\sigma^{2}}{2} x^{2} d_{H_{0}}^{\prime \prime}(x)+\lambda_{H}\left[d_{L_{0}}(x)-d_{H_{0}}(x)\right]+c .
\end{array}\right.
$$

From the above system we can obtain a set of two independent ODEs using $j(x)=d_{H_{0}}(x)-d_{L_{0}}(x)$ and $z(x)=\lambda_{L} d_{H_{0}}(x)+\lambda_{H} d_{L_{0}}(x)$. 4.3) can be rewritten 
in term of $j(x)$ and $z(x)$ as

$$
\begin{gathered}
\left(r+\lambda_{H}+\lambda_{L}\right) j(x)=\mu x j^{\prime}(x)+\frac{\sigma^{2}}{2} x^{2} j^{\prime \prime}(x) \\
r z(x)=\mu x z^{\prime}(x)+\frac{\sigma^{2}}{2} x^{2} z^{\prime \prime}(x)+\left(\lambda_{L}+\lambda_{H}\right) c
\end{gathered}
$$

with the following general solutions

$$
\begin{aligned}
& j(x)=J_{1} x^{\gamma_{1}}+J_{2} x^{\gamma_{2}} \\
& z(x)=Z_{1} x^{\xi_{1}}+Z_{2} x^{\xi_{2}}+\frac{\left(\lambda_{L}+\lambda_{H}\right) c}{r}
\end{aligned}
$$

$\gamma_{i}, \xi_{i}, i=1,2$, in 4.4 and 4.5 are respectively the negative and positive roots of the following quadratic equations

$$
\begin{gathered}
\left(r+\lambda_{H}+\lambda_{L}\right)-\left(\mu-\frac{\sigma^{2}}{2}\right) \gamma-\frac{\sigma^{2}}{2} \gamma^{2}=0 \\
r-\left(\mu-\frac{\sigma^{2}}{2}\right) \xi-\frac{\sigma^{2}}{2} \xi^{2}=0 .
\end{gathered}
$$

Given the positive sign of $\gamma_{2}$ and $\xi_{2}$, the linear growth conditions

$$
\lim _{x \uparrow \infty} \frac{j(x)}{x}<\infty, \lim _{x \uparrow \infty} \frac{z(x)}{x}<\infty
$$

impose $J_{2}=0$ and $Z_{2}=0$. Substituting back $j(x)=d_{H_{0}}(x)-d_{L_{0}}(x)$ and $z(x)=\lambda_{L} d_{H_{0}}(x)+\lambda_{H} d_{L_{0}}(x)$ and rearranging we obtain

$$
\begin{aligned}
d_{H_{0}}(x) & =\frac{\lambda_{H}}{\lambda_{L}+\lambda_{H}} J_{1} x^{\gamma_{1}}+\frac{1}{\lambda_{L}+\lambda_{H}} Z_{1} x^{\xi_{1}}+\frac{c}{r} \\
d_{L_{0}}(x) & =-\frac{\lambda_{L}}{\lambda_{L}+\lambda_{H}} J_{1} x^{\gamma_{1}}+\frac{1}{\lambda_{L}+\lambda_{H}} Z_{1} x^{\xi_{1}}+\frac{c}{r} .
\end{aligned}
$$

Imposing the boundary conditions

$$
\begin{aligned}
d_{L_{0}}\left(x_{L_{0}}^{*}\right) & =d_{L_{1}}\left(x_{L_{0}}^{*}\right) \\
d_{H_{0}}\left(x_{H_{0}}^{*}\right) & =\delta \alpha_{H_{0}} A_{H}\left(x_{H_{0}}^{*}\right) \\
\lim _{x \downarrow x_{L_{0}}^{*}} d_{H_{0}}(x) & =\lim _{x \uparrow x_{L_{0}}^{*}} d_{H_{0}}(x) \\
\lim _{x \downarrow x_{L_{0}}^{*}} d_{H_{0}}^{\prime}(x) & =\lim _{x \uparrow x_{L_{0}}^{*}} d_{H_{0}}^{\prime}(x)
\end{aligned}
$$


we obtain the debt value in the two states:

$$
\begin{gathered}
d_{L_{0}}(x)= \begin{cases}-\frac{\lambda_{L}}{\left(\lambda_{L}+\lambda_{H}\right)} J_{1} x^{\gamma_{1}}+\frac{1}{\left(\lambda_{L}+\lambda_{H}\right)} Z_{1} x^{\xi_{1}}+\frac{c}{r}, & x>x_{L_{0}}^{*} \\
A_{d} x^{\xi}-\lambda_{L} B_{d} x^{\gamma}+\frac{c}{r}, & x \leq x_{L_{0}}^{*}\end{cases} \\
d_{H_{0}}(x)= \begin{cases}\frac{\lambda_{H}}{\left(\lambda_{L}+\lambda_{H}\right)} J_{1} x^{\gamma_{1}}+\frac{1}{\left(\lambda_{L}+\lambda_{H}\right)} Z_{1} x^{\xi_{1}}+\frac{c}{r}, & x>x_{L_{0}}^{*} \\
U_{1} x^{\phi_{1}}+U_{2} x^{\phi_{2}}+\lambda_{H} y_{p}(x)+\frac{c}{r+\lambda_{H}}, & x_{H_{0}}^{*}<x \leq x_{L_{0}}^{*} \\
\delta \alpha_{H_{0}} K_{H}(1-\tau) x, & x \leq x_{H_{0}}^{*}\end{cases}
\end{gathered}
$$

where the constants in the above formulae are contained in $\mathrm{C}$

A coupon dependent $\delta$ (e.g. equal to the par value ratio $c /(c+c c)$ ) does not affect the optimal coupons of straight debt and of CCC. This is due to the fact that the optimal barriers and the firm value don't depend on $\delta$. The only effect of a change in $\delta$ is on the portion of firm value of CCC and of straight debtholders in case of bankruptcy. As a consequence a change of $\delta$ doesn't affect the optimal leverage but only the spread of debt instruments.

\subsection{Countercyclical Contingent Capital}

Before conversion, CCC holders receive a continuous coupon payment $c c$. We assume that at conversion contingent capital holders receive a fraction $\theta$ as defined in (2.1) of the equity value in Period 1, i.e., contingent capital holders receive a fraction of equity value equal to the par value of the certificates.

Conversion takes place only if macroeconomic conditions are bad, i.e., state $L$, and the lower barrier $x_{L_{0}}^{*}$ is touched. On the other hand, if the lower barrier $x_{H_{0}}^{*}$ is touched when the macroeconomic state is good, then CCC holders concur with debtholders to obtain the abandonment value of the company after bankruptcy. As debtholders obtain the fraction $\delta$ of the recovery value, the remaining fraction $(1-\delta)$ goes to CCC holders. The contingent capital certificate value in the two states $C C C_{i_{0}}(x), i=L, H$, has to satisfy the following set of ODEs:

- if $x_{H_{0}}^{*} \leq x \leq x_{L_{0}}^{*}$ :

$$
r C C C_{H_{0}}(x)=\mu x C C C_{H_{0}}^{\prime}(x)+\frac{\sigma^{2}}{2} x^{2} C C C_{H_{0}}^{\prime \prime}(x)+\lambda_{H}\left[\theta e_{L_{1}}(x)-C C C_{H_{0}}(x)\right]+c c
$$


with general solution:

$$
C C C_{H_{0}}(x)=U_{1} x^{\phi_{1}}+U_{2} x^{\phi_{2}}+\lambda_{H} y_{p}(x)+\frac{c c}{r+\lambda_{H}}
$$

where:

$$
y_{p}(x)=\left(\int-\frac{2 x^{-\left(1+\phi_{1}\right)} \theta e_{L_{1}}(x)}{\left(\phi_{1}-\phi_{2}\right) \sigma^{2}} d x\right) x^{\phi_{1}}+\left(\int \frac{2 x^{-\left(1+\phi_{2}\right)} \theta e_{L_{1}}(x)}{\left(\phi_{1}-\phi_{2}\right) \sigma^{2}} d x\right) x^{\phi_{2}}
$$

- if $x>x_{L_{0}}^{*}$ :

$$
\left\{\begin{array}{l}
r C C C_{L_{0}}(x)=\mu x C C C_{L_{0}}^{\prime}(x)+\frac{\sigma^{2}}{2} x^{2} C C C_{L_{0}}^{\prime \prime}(x)+\lambda_{L}\left[C C C_{H_{0}}(x)-C C C_{L_{0}}(x)\right]+c c \\
r C C C_{H_{0}}(x)=\mu x C C C_{H_{0}}^{\prime}(x)+\frac{\sigma^{2}}{2} x^{2} C C C_{H_{0}}^{\prime \prime}(x)+\lambda_{H}\left[C C C_{L_{0}}(x)-C C C_{H_{0}}(x)\right]+c c
\end{array}\right.
$$

with general solutions

$$
\begin{aligned}
C C C_{H_{0}}(x) & =\frac{\lambda_{H}}{\left(\lambda_{L}+\lambda_{H}\right)} J_{1} x^{\gamma_{1}}+\frac{1}{\left(\lambda_{L}+\lambda_{H}\right)} Z_{1} x^{\xi_{1}}+\frac{c c}{r} \\
C C C_{L_{0}}(x) & =-\frac{\lambda_{L}}{\left(\lambda_{L}+\lambda_{H}\right)} J_{1} x^{\gamma_{1}}+\frac{1}{\left(\lambda_{L}+\lambda_{H}\right)} Z_{1} x^{\xi_{1}}+\frac{c c}{r} .
\end{aligned}
$$

Imposing the boundary conditions

$$
\begin{aligned}
C C C_{L_{0}}\left(x_{L_{0}}^{*}\right) & =\theta e_{L_{1}}\left(x_{L_{0}}^{*}\right) \\
C C C_{H_{0}}\left(x_{H_{0}}^{*}\right) & =(1-\delta) \alpha_{H_{0}} A_{H}\left(x_{H_{0}}^{*}\right) \\
\lim _{x \uparrow x_{L_{0}}^{*}} C C C_{H_{0}}(x, c c) & =\lim _{x \downarrow x_{L_{0}}^{*}} C C C_{H_{0}}(x, c c) \\
\lim _{x \uparrow x_{L_{0}}^{*}} C C C_{H_{0}}^{\prime}(x, c c) & =\lim _{x \downarrow x_{L_{0}}^{*}} C C C_{H_{0}}^{\prime}(x, c c)
\end{aligned}
$$

we obtain

$$
\begin{gathered}
C C C_{L_{0}}(x)= \begin{cases}-\frac{\lambda_{L}}{\left(\lambda_{L}+\lambda_{H}\right)} J_{1} x^{\gamma_{1}}+\frac{1}{\left(\lambda_{L}+\lambda_{H}\right)} Z_{1} x^{\xi_{1}}+\frac{c c}{r}, & x>x_{L_{0}}^{*} \\
\theta\left[A_{e} x^{\xi}-\lambda_{L} B_{e} x^{\gamma}+(1-\tau)\left(K_{L} x-\frac{c}{r}\right)\right], & x \leq x_{L_{0}}^{*}\end{cases} \\
C C C_{H_{0}}(x)= \begin{cases}\frac{\lambda_{H}}{\left(\lambda_{L}+\lambda_{H}\right)} J_{1} x^{\gamma_{1}}+\frac{1}{\left(\lambda_{L}+\lambda_{H}\right)} Z_{1} x^{\xi_{1}}+\frac{c c}{r}, & x>x_{L_{0}}^{*} \\
U_{1} x^{\phi_{1}}+U_{2} x^{\phi_{2}}+\lambda_{H} y_{p}(x)+\frac{c c}{r+\lambda_{H}}, & x_{H_{0}}^{*}<x \leq x_{L_{0}}^{*} \\
(1-\delta) \alpha_{H_{0}} K_{H}(1-\tau) x, & x \leq x_{H_{0}}^{*} .\end{cases}
\end{gathered}
$$

C contains all the details of the above formulae. 


\subsection{Firm Value}

The total firm value is given by the sum of the present value of the unlimited after tax income stream and the present value of the unlimited tax benefit of debt and contingent capital minus bankruptcy costs. Indicating the company value with $v_{i_{0}}(x), 1=L, H$, by Itô Lemma we have the following set of ODEs:

- if $x_{H_{0}}^{*} \leq x \leq x_{L_{0}}^{*}$ :

$$
r v_{H_{0}}(x)=\mu x v_{H_{0}}^{\prime}(x)+\frac{\sigma^{2}}{2} x^{2} v_{H_{0}}^{\prime \prime}(x)+\lambda_{H}\left[v_{L_{1}}(x)-v_{H_{0}}(x)\right]+(1-\tau) x y_{H}+(c+c c) \tau
$$

the general solution of the above equation is

$$
v_{H_{0}}(x)=U_{1} x^{\phi_{1}}+U_{2} x^{\phi_{2}}+\lambda_{H} y_{p}(x)+\frac{(1-\tau) x y_{H}}{r+\lambda_{H}-\mu}+\frac{(c c+c) \tau}{r+\lambda_{H}}
$$

with

$$
y_{p}(x)=\left(\int-\frac{2 x^{-\left(1+\phi_{1}\right)} v_{L_{1}}(x)}{\left(\phi_{1}-\phi_{2}\right) \sigma^{2}} d x\right) x^{\phi_{1}}+\left(\int \frac{2 x^{-\left(1+\phi_{2}\right)} v_{L_{1}}(x)}{\left(\phi_{1}-\phi_{2}\right) \sigma^{2}} d x\right) x^{\phi_{2}}
$$

- if $x>x_{L_{0}}^{*}$ :

$$
\left\{\begin{array}{l}
r v_{L_{0}}(x)=\mu x v_{L_{0}}^{\prime}(x)+\frac{\sigma^{2}}{2} x^{2} v_{L_{0}}^{\prime \prime}(x)+\lambda_{L}\left[v_{H_{0}}(x)-v_{L_{0}}(x)\right]+(1-\tau) x y_{L}+(c+c c) \tau \\
r v_{H_{0}}(x)=\mu x v_{H_{0}}^{\prime}(x)+\frac{\sigma^{2}}{2} x^{2} v_{H_{0}}^{\prime \prime}(x)+\lambda_{H}\left[v_{L_{0}}(x)-v_{H_{0}}(x)\right]+(1-\tau) x y_{H}+(c+c c) \tau
\end{array}\right.
$$

the general solution of the above equation is

$$
\begin{aligned}
& v_{H_{0}}(x)=\frac{\lambda_{H}}{\left(\lambda_{L}+\lambda_{H}\right)} J_{1} x^{\gamma_{1}}+\frac{1}{\left(\lambda_{L}+\lambda_{H}\right)} Z_{1} x^{\xi_{1}}+(1-\tau) K_{H} x+\frac{\tau(c+c c)}{r} \\
& v_{L_{0}}(x)=-\frac{\lambda_{L}}{\left(\lambda_{L}+\lambda_{H}\right)} J_{1} x^{\gamma_{1}}+\frac{1}{\left(\lambda_{L}+\lambda_{H}\right)} Z_{1} x^{\xi_{1}}+(1-\tau) K_{L} x+\frac{\tau(c+c c)}{r} .
\end{aligned}
$$

Imposing the boundary conditions

$$
\begin{aligned}
v_{L_{0}}\left(x_{L_{0}}^{*}\right) & =v_{L_{1}}\left(x_{L_{0}}^{*}\right) \\
v_{H_{0}}\left(x_{H_{0}}^{*}\right) & =\alpha_{H_{0}} A_{H}\left(x_{H_{0}}^{*}\right) \\
\lim _{x \uparrow x_{L_{0}}^{*}} v_{H_{0}}(x) & =\lim _{x \downarrow x_{L_{0}}^{*}} v_{H_{0}}(x) \\
\lim _{x \uparrow x_{L_{0}}^{*}} v_{H_{0}}^{\prime}(x) & =\lim _{x \downarrow x_{L_{0}}^{*}} v_{H_{0}}^{\prime}(x)
\end{aligned}
$$


we obtain

$$
\begin{gathered}
v_{L_{0}}(x)= \begin{cases}-\frac{\lambda_{L}}{\left(\lambda_{L}+\lambda_{H}\right)} J_{1} x^{\gamma_{1}}+\frac{1}{\left(\lambda_{L}+\lambda_{H}\right)} Z_{1} x^{\xi_{1}}+(1-\tau) K_{L} x+\frac{\tau(c+c c)}{r}, & x>x_{L_{0}}^{*} \\
A_{v} x^{\xi}-\lambda_{L} B_{v} x^{\gamma}+(1-\tau) K_{L} x+\frac{\tau c}{r}, & x \leq x_{L_{0}}^{*}\end{cases} \\
v_{H_{0}}(x)= \begin{cases}\frac{\lambda_{H}}{\left(\lambda_{L}+\lambda_{H}\right)} J_{1} x^{\gamma_{1}}+\frac{1}{\left(\lambda_{L}+\lambda_{H}\right)} Z_{1} x^{\xi_{1}}+(1-\tau) K_{H} x+\frac{\tau(c+c c)}{r}, & x>x_{L_{0}}^{*} \\
U_{1} x^{\phi_{1}}+U_{2} x^{\phi_{2}}+\lambda_{H} y_{p}(x)+\frac{(1-\tau) y_{H} x}{r+\lambda_{H}-\mu}+\frac{\tau(c c+c)}{r+\lambda_{H}}, & x_{H_{0}}^{*}<x \leq x_{L_{0}}^{*} \\
\alpha_{H_{0}} K_{H}(1-\tau) x, & x \leq x_{H_{0}}^{*} .\end{cases}
\end{gathered}
$$

C] contains all the details of the above formulae.

\subsection{Equity Value}

Given the value of the firm, the value of debt and that of contingent capital, the value of equity is simply obtained as the difference:

$$
\begin{gathered}
e_{L_{0}}(x)= \begin{cases}v_{L_{0}}(x)-d_{L_{0}}(x)-C C C_{L_{0}}(x) & \text { if } x>x_{L_{0}}^{*} \\
(1-\theta) e_{L_{1}}(x) & \text { if } x \leq x_{L_{0}}^{*}\end{cases} \\
e_{H_{0}}(x)= \begin{cases}v_{H_{0}}(x)-d_{H_{0}}(x)-C C C_{H_{0}}(x) & \text { if } x>x_{L_{0}}^{*} \\
v_{H_{0}}(x)-d_{H_{0}}(x)-C C C_{H_{0}}(x) & \text { if } \quad x_{H_{0}}^{*}<x \leq x_{L_{0}}^{*} \\
0 & \text { if } \quad x \leq x_{H_{0}}^{*} .\end{cases}
\end{gathered}
$$

\section{Optimal Capital Structure}

The optimal capital structure is chosen by the three claim holders, i.e., equity, straight debt and CCC holders. Taking the conversion barrier defined by the authority as given, equity holders define the bankruptcy barrier in Period $1\left(x_{H_{1}}^{*}, x_{L_{1}}^{*}\right)$ and the bankruptcy barrier in Period 0 for a good state of the economy $\left(x_{H_{0}}^{*}\right)$.

The bankruptcy level $x_{H_{0}}^{*}$ is chosen by equity holders through smooth pasting conditions. The condition requires

$$
\left.\frac{\partial e_{H_{0}}(x)}{\partial x}\right|_{x=x_{H_{0}}^{*}}=0 .
$$


As already discussed, conversion takes place only if $y(t)=y_{L}$ and $x(t)<x_{L_{0}}^{*}$. We could assume $x_{L_{0}}^{*}$ to be determined according to the probability of default. Since after conversion the bank can default in both the macroeconomic conditions the probability of default would be a function of the distance between $x$ and $x_{L_{1}}^{*}, x_{H_{1}}^{*}$, see Barucci and Del Viva 2010]. The drawback of using this proxy to drive conversion is that we would obtain a conversion barrier independent of $c c$. This assumption is unrealistic and renders the optimal capital structure problem unbounded. We prefer to assume that the regulatory authority defines the conversion barrier in a prudent way multiplying the bankruptcy barrier in a good state $\left(x_{H_{0}}^{*}\right)$ decided by equity holders for a constant $R_{0}>1$, so $x_{L_{0}}^{*}=x_{H_{0}}^{*} R_{0}$. This assumption is plausible, indeed, if shareholders are free to decide a bankruptcy strategy in the bad state of the economy then they will fix a $x_{L_{0}}^{*}>x_{H_{0}}^{*}$ as in Period 1.

Given the optimal barriers, optimal coupons are obtained maximizing the value of the company in the two states, see Leland [1994:

$$
\left.\max _{c, c c} v_{i}\left(x_{0}\right)\right|_{x_{H_{0}}=x_{H_{0}}^{*}, x_{L_{0}}=x_{L_{0}}^{*}}, \quad i=H, L
$$

where $v_{i}\left(x_{0}\right)=e_{i}\left(x_{0}\right)+d_{i}\left(x_{0}\right)+C C C_{i}\left(x_{0}\right)$ and where we have already substituted $x_{L_{1}}^{*}$ and $x_{H_{1}}^{*}$ in the claim values of Period 1. Optimal coupons depend on the initial macroeconomic conditions, so we have different optimal coupons in the two regimes: $\left(c^{*}, c c^{*}\right)_{L},\left(c^{*}, c c^{*}\right)_{H}$ depending on the state of the economy when the capital structure is defined.

An alternative assumption on the conversion rule would be to consider a triggering barrier defined as a fraction of the par value of the two debt like instruments $\left(\Lambda\left(\frac{c c+c}{r}\right)\right)$ see Barucci and Del Viva [2010]. The main results of the analysis proposed below are confirmed in this setting. 


\begin{tabular}{ll}
\hline Variable & Parameters \\
\hline risk free interest rate & $r=0.055$ \\
initial level of cash flow & $x_{0}=1$ \\
growth rate of cash flow & $\mu=0.005$ \\
volatility of cash flow & $\sigma=0.25$ \\
tax advantage of debt & $\tau=0.15$ \\
recovery rates (period 1) & $\alpha_{H}=\alpha_{L}=0.6$ \\
recovery rate (period 0) & $\alpha_{H_{0}}=0.5$ \\
\% recovery for straight debt holders & $\delta=0.7$ \\
persistence of shocks & $\lambda_{L}=0.15, \lambda_{H}=0.1$ \\
size of shocks & $y_{L}=0.9, y_{H}=1.1$ \\
distance barrier period 0 & $R_{0}=1.2 \quad\left(x_{L_{0}}^{*}=R_{0} \times x_{H_{0}}^{*}\right)$ \\
\hline
\end{tabular}

Table 2: Initial parameters choice.

\section{Comparative Statics}

In this Section we illustrate the main effects on the capital structure of a bank when the parameters of the model change. We assume that the capital structure is defined in a good state which seems to be the more interesting and plausible case, we leave the analysis of the bad state to Section 8 . Our analysis starts from the parameter set in Table 2.

Note that an increase of coupons play two main effects on the value of debt: on one hand the cash flow of the note before bankruptcy goes up, on the other the default/conversion barriers go up and this leads to a lower value of debt like instruments. These two effects may induce a nonlinear relationship between coupon/spread and leverage: depending on the two mechanisms we may have a company with a large spread and a large or a small leverage.

Three main observations arise from the analysis:

1) leverage with CCC is higher than in a classical setting but the difference is relatively 
small;

2) the spread of CCC is always higher than that of straight debt and it is extremely sensitive to volatility;

3) the spread of straight debt is reduced significantly by the issue of CCC which captures large part of company risk.

\section{a) Variation of $\lambda_{L}$ and $\lambda_{H}$}

$\lambda_{L}$ represents the rate of leaving the state $L$ for the state $H$. As we are analyzing the optimal capital structure decision in a good state of the economy, an increase of $\lambda_{L}$ indicates an increase in the probability of turning back to the original state $H$ conditional on a previous crisis. Note that an increase of $\lambda_{L}$ plays two different roles: on one hand it expresses the probability of leaving the state where there isn't the possibility of default for the state where the bank can default, on the other hand it expresses the probability of leaving the state with bad performance for the state with good performance. So as $\lambda_{L}$ goes up we have a greater probability to have a good performance but also to have default escaping the conversion in equity for CCC holders. Figure 2 shows that an increase of $\lambda_{L}$ reduces both the optimal leverage and the spread of CCC. The rationale is that CCC looks like straight debt as the probability of moving to the good state increases. These results show that increasing $\lambda_{L}$ the company becomes safer: the increase in the probability of a recovery conditional on a crisis state balances a higher bankruptcy risk. Claim holders enjoy a smaller probability of conversion and therefore the spread on CCC goes down. In the limit, as $\lambda_{L}$ increases, CCC becomes similar to straight debt and leverage is at the level of a standard company. The spread of straight debt is almost constant and equal to half the spread obtained without CCC.

$\lambda_{H}$ represents the rate of leaving the state $H$ for the state $L$. An increase in $\lambda_{H}$ produces specular results to those observed for $\lambda_{L}$ : the bank becomes more risky, the spread of CCCs goes up and consequently the optimal leverage increases. In the limit, as $\lambda_{H}$ goes to zero, CCC becomes similar to straight debt and leverage is at the level of a standard company. For CCC holders the probability of conversion in a bad state is a risky factor that prevails over the risk of default in a good state. 

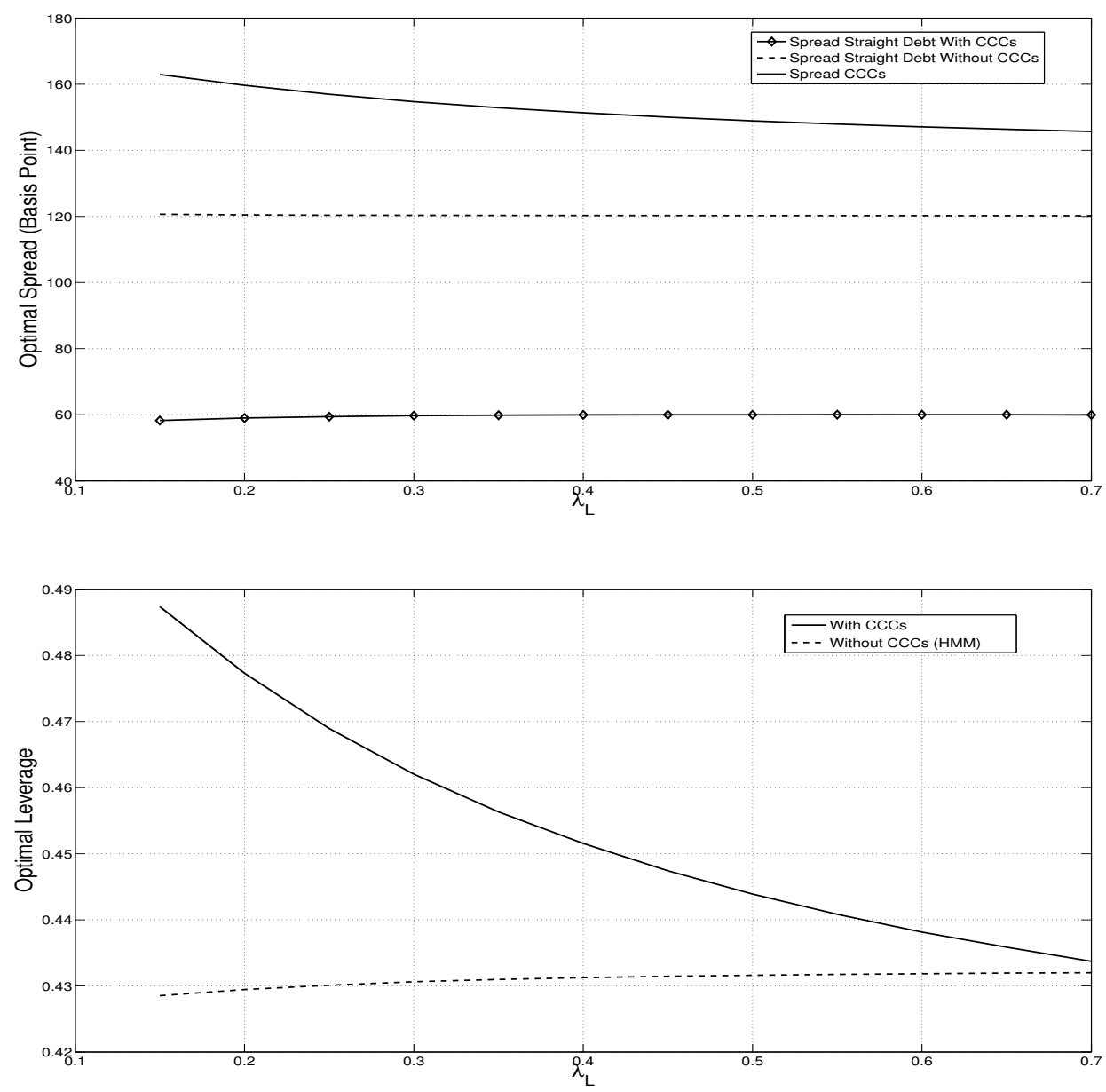

Figure 2: Effect produced by a change in $\lambda_{L}$ on spreads and leverage when the capital structure is decided in good macroeconomic conditions. Both figures compare the optimal spreads and leverage obtained in our model with the results obtained without CCCs, i.e., the standard Hackbarth et al. 2006 model. 


\section{b) Variation of $\sigma$}

$\sigma$ is the volatility of the idiosyncratic part of the EBIT. It represents a proxy of the riskiness of the company. As the volatility of the company goes up the spread of both debt like instruments increase and the leverage ratio decreases, see Figure 3 . Note that the increase of the spread of CCC is much higher than that of straight debt and that the spread of straight debt is reduced significantly by CCC when volatility is high. The spread of CCC is higher than that of straight debt. These results suggest that CCC absorbs large part of the risk of the company. The rationale of the decoupling between leverage and spread is that a volatility increase augments significantly the barrier and the probability of bankruptcy, and therefore the value of debt decreases while that of equity goes up. On the optimal leverage we have another effect, indeed the optimal debt ratio is obtained balancing the trade off between tax benefit of debt and bankruptcy costs. An increase of volatility reduces the probability of a long maturity for the debt and therefore the tax benefit is limited, this leads to a reduction of the optimal leverage. We can conclude that the bankruptcy barrier goes up and the company becomes riskier as volatility goes up. CCC captures large part of risk of straight debt and there is a substitution between CCC and straight debt, see Figure 3, as long as volatility goes up, CCC is issued in place of straight debt or in other words its value goes up much more than that of straight debt.

c) Variation of $\alpha_{H}=\alpha_{L}$ and of $\alpha_{H_{0}}$ An increase in the value of $\alpha_{H}=\alpha_{L}$ leads to an increase of the recovery value of debt and thus to a reduction of bankruptcy costs in Period 1, i.e., bankruptcy costs only for straight bondholders. A reduction of bankruptcy costs reduces the cost of straight debt in Period 1. This provides an incentive to increase the coupon (and a higher spread) of straight debt, an incentive that is reinforced by the higher tax benefit. The increase of the coupon of straight debt produces an increase of bankruptcy risk, to maintain the risk at a reasonable level and to exploit the incremental advantage of straight debt, the coupon of CCC is reduced. As a consequence, we have more straight debt instead of CCC, see Figure 4. The substitution between straight debt and CCC is almost perfect 

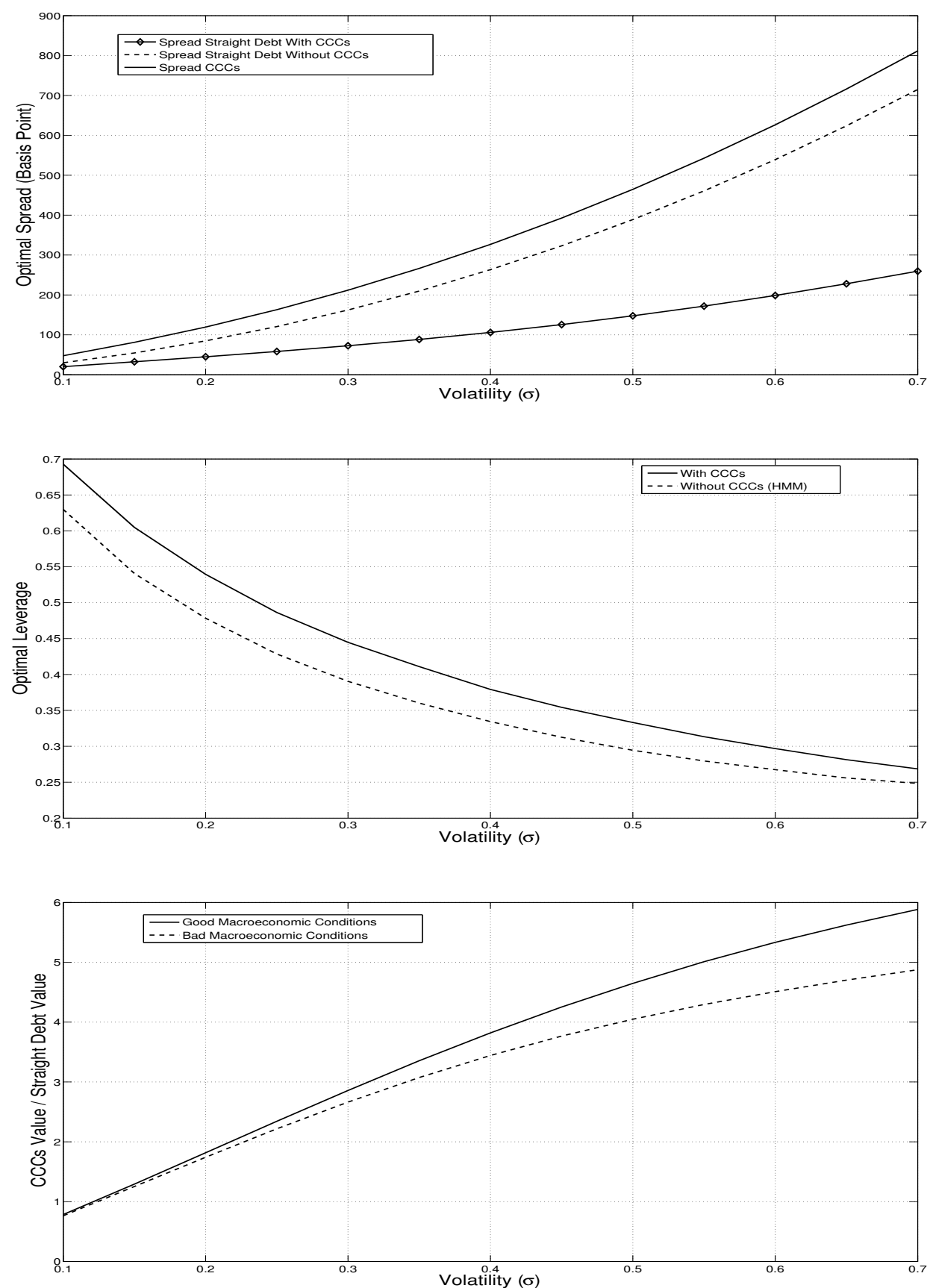

Figure 3: Effect produced by a change in $\sigma$ on spreads, leverage and debt structure. The first two figures compare the optimal spreads and leverage obtained in our model with the results obtained without CCCs, i.e., the standard Hackbarth et al. 2006 model. 
with a constant leverage. This analysis is confirmed by the fact that the leverage ratio would go up in case CCCs are not issued.

The effect of a reduction of bankruptcy costs in Period $0\left(\alpha_{H_{0}}\right)$ is more complex. Indeed a reduction of the bankruptcy cost in period 0, i.e., an increase in $\alpha_{H_{0}}$, increases the optimal coupon of straight debt and of CCC. This would lead to a higher spread for both debt like instruments via a higher probability of default. However, the value of CCC is negatively affected by a higher coupon of straight debt because it increases the probability of conversion and this reduces its value. Instead an increase of the coupon of straight debt, though it will increase the bankruptcy risk in both periods, produces a higher tax benefit and a higher value. These effects explain why a reduction of bankruptcy costs in Period 0 leads the bank to prefer straight debt to CCC and to a higher spread of CCC and a smaller spread of straight debt, see Figure 5.

\section{$7 \quad$ CCC and Asset Substitution Incentives}

In this Section we investigate whether the inclusion of CCC in the capital structure of a company changes the incentive of shareholders to invest in risky projects once all the claims have been issued. Typically, given the particular shape of the equity value function and the limited liability assumption, shareholders have the incentive to increase the riskiness of the company once debt has been issued (asset substitution incentive).

We focus on the case of a good state of the economy. Suppose that the volatility of the cash flow returns of the bank is $\sigma=10 \%$, the other parameter values are as in Table 2, for this level of volatility the following optimal strategy results: 1 :

\footnotetext{
${ }^{1}$ In order to speed up the calculations these optimal values are obtained numerically by imposing a value step for the coupons of both CCC and straight debt of 0.005 , thus the coupons are calculated with an error at most equal to the $0.5 \%$ of the initial EBIT value of 1 . For this reason these values could be slightly different from those used in the comparative statics Section where we use a value step of 0.0001 .
} 

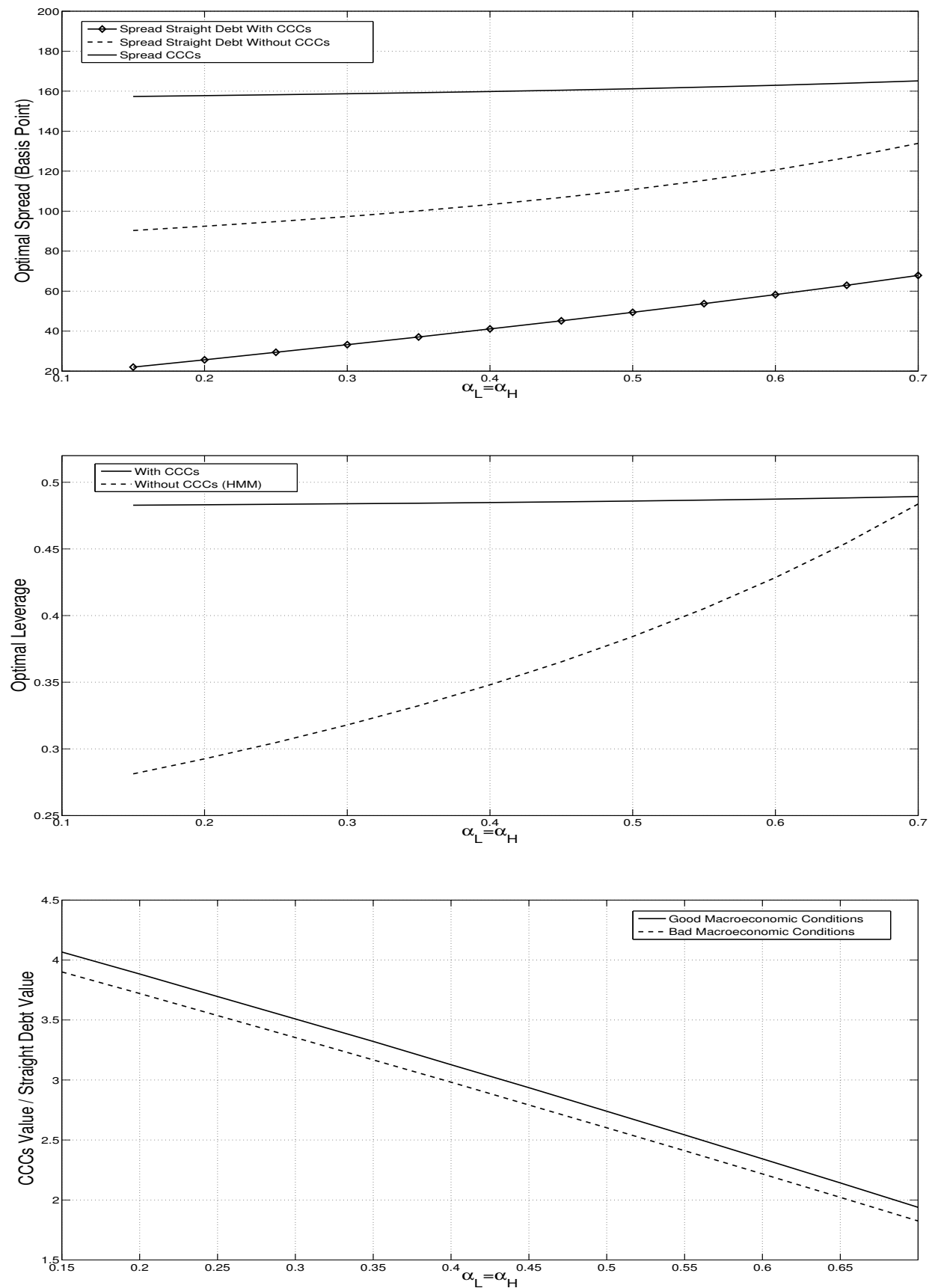

Figure 4: Effects produced by a change in $\alpha_{L}=\alpha_{H}$ on spreads, leverage and debt structure. The first two figures compare the spreads and leverage obtained in our model with the results obtained without CCCs, i.e., the standard Hackbarth et al. 2006 model. 

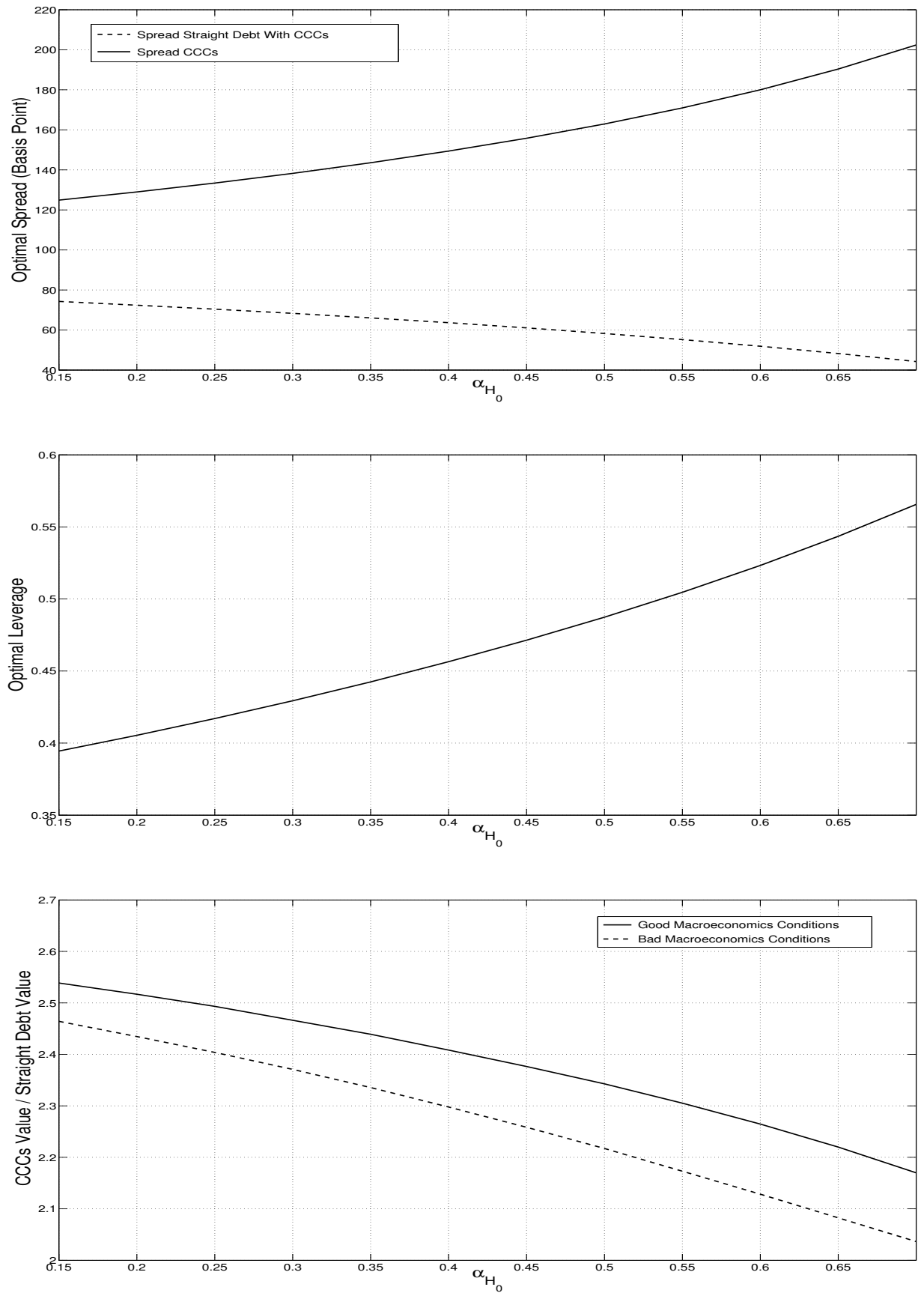

Figure 5: Effects produced by a change in $\alpha_{H_{0}}$ on spreads, leverage and debt structure. Obviously given the absence of $\alpha_{H_{0}}$ in the model of Hackbarth et al. 2006 it is not possible to make a comparison of the results. 
- Good states of the economy: $x_{H_{0}}^{*}=0.5198, x_{L_{0}}^{*}=0.6238, x_{H_{1}}^{*}=0.2824$, $x_{L_{1}}^{*}=0.3016, c^{*}=0.425, c c^{*}=0.35, e_{H_{0}}^{*}=5.8985, x_{H M M_{H}}^{*}=0.4618, x_{H M M_{L}}^{*}=$ $0.4933, c_{H M M}^{*}=0.695, e_{H M M}^{*}=7.039$;

- Bad states of the economy: $x_{H_{0}}^{*}=0.5567, x_{L_{0}}^{*}=0.6680, x_{H_{1}}^{*}=0.3023$, $x_{L_{1}}^{*}=0.3230, c^{*}=0.455, c c^{*}=0.375, e_{L_{0}}^{*}=4.5816, x_{H M M_{H}}^{*}=0.4585, x_{H M M_{L}}^{*}=$ $0.4898, c_{H M M}^{*}=0.69, e_{H M M}^{*}=6.5440$;

where the lower script $H M M$ refers to optimal values obtained in the model of Hackbarth et al. 2006, that is a capital structure composed only of equity and straight debt and where the company defaults in both states of the economy. In Figure 6 and 7 we show the increase in equity value as the ex post volatility increases. In particular the first picture of each figure shows the equity value as a function of the ex-post volatility; the second picture depicts the ratio $\frac{e(\sigma)-e(\sigma=0.1)}{e(\sigma=0.1)}$ as a function of the ex post volatility; the third picture illustrates the first derivative of the equity value as a function of the ex post volatility, i.e., the first derivative of the function in the first picture. Since bankruptcy barriers are chosen by equity holders, we assume that they change their default strategy as the volatility changes. In particular we assume that bankruptcy barriers change according to the smooth pasting conditions, while the conversion barrier remains constant as fixed by the authority at the time straight debt and CCC are issued with volatility $\sigma=0.1$. Note that bankruptcy barriers are decreasing functions of volatility and this ensures that the initial conversion barrier for $\sigma=0.1$ is always higher than the theoretical bankruptcy barrier would be for $\sigma>0.1$. Figure 6 shows the asset substitution incentive when the bankruptcy barriers change for different values of $\lambda_{H}$. A similar picture is obtained for different values of $\lambda_{L}$. The Figure shows that allowing shareholders to revise their bankruptcy strategy (barriers) the incentive to increase the risk of the company is always lower when also CCCs are issued. The reduction of the incentive is higher the higher is the probability of a crisis, i.e., high $\lambda_{H}$. Our results confirm those obtained in Albul et al. [2010] when contingent capital certificates are introduced by swapping contingent for straight debt. 

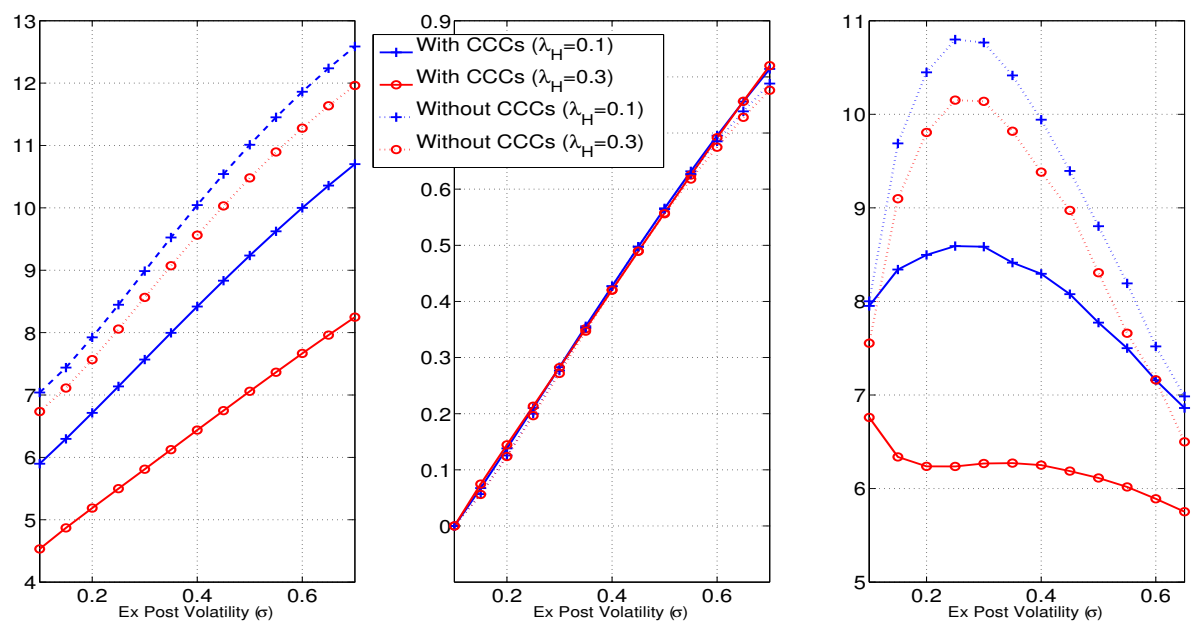

Figure 6: Asset substitution incentive when the optimal capital structure is decided in good macroeconomic conditions and the bankruptcy barriers vary with the volatility for different values of $\lambda_{H}$. The first picture on the left hand side depicts the value of the equity as a function of the ex post volatility $e(\sigma)$; the second picture shows the values of $\frac{e(\sigma)-e(\sigma=0.1)}{e(\sigma=0.1)}$; the last picture shows $\partial e(\sigma) / \partial \sigma$, i.e., the derivative of the first picture. 
To complete the analysis we consider the asset substitution incentive in a bad state of the economy when the capital structure has been defined in a good state. This exercise shows us the incentive in adopting a riskier technology in a crisis period. Figure 7 shows the asset substitution incentive when the capital structure is defined in a good macroeconomic condition but it immediately turns to bad for different values of $\lambda_{H}$. In this case the presence of $\mathrm{CCC}$ reduces the incentive to adopt a riskier technology. While the bankruptcy barriers are chosen by equity holders optimally, i.e., they choose the bankruptcy barriers knowing that the new macroeconomic conditions are bad, the optimal coupons and the conversion barrier remain fixed at the optimal value for the first level of volatility and for the good state of the economy. The asset substitution incentive is reduced significantly by CCC and the reduction is higher the higher is the probability of the onset of a crisis (high $\lambda_{H}$ ). These results are confirmed allowing the authority to change the conversion barrier in the bad state (as it would have been in the bad macroeconomic condition).

\section{The Bad Macroeconomic State}

In the previous sections we have analyzed the capital structure of a bank when decisions are taken in a good state, we now analyze the problem when decisions are taken in a bad state, e.g., the company issues CCC in the middle of a crisis. Figures 8 and 9 show the sensitivity of spreads and of leverage to volatility when the capital structure decision is taken in a bad state.

Even if bankruptcy is not allowed in the actual state, as volatility increases the company becomes riskier and the spread of both debt like instruments goes up. Comparing Figure 9 (bad state) with Figure 3 (good state) we observe that the spread of CCC is much higher than in a good state. Compared to the good macroeconomic state, the main difference concerns the optimal leverage. The optimal leverage is not a monotonic (decreasing) function of volatility. For a high level of volatility the optimal leverage is higher than in a good macroeconomic state and is is an increasing 

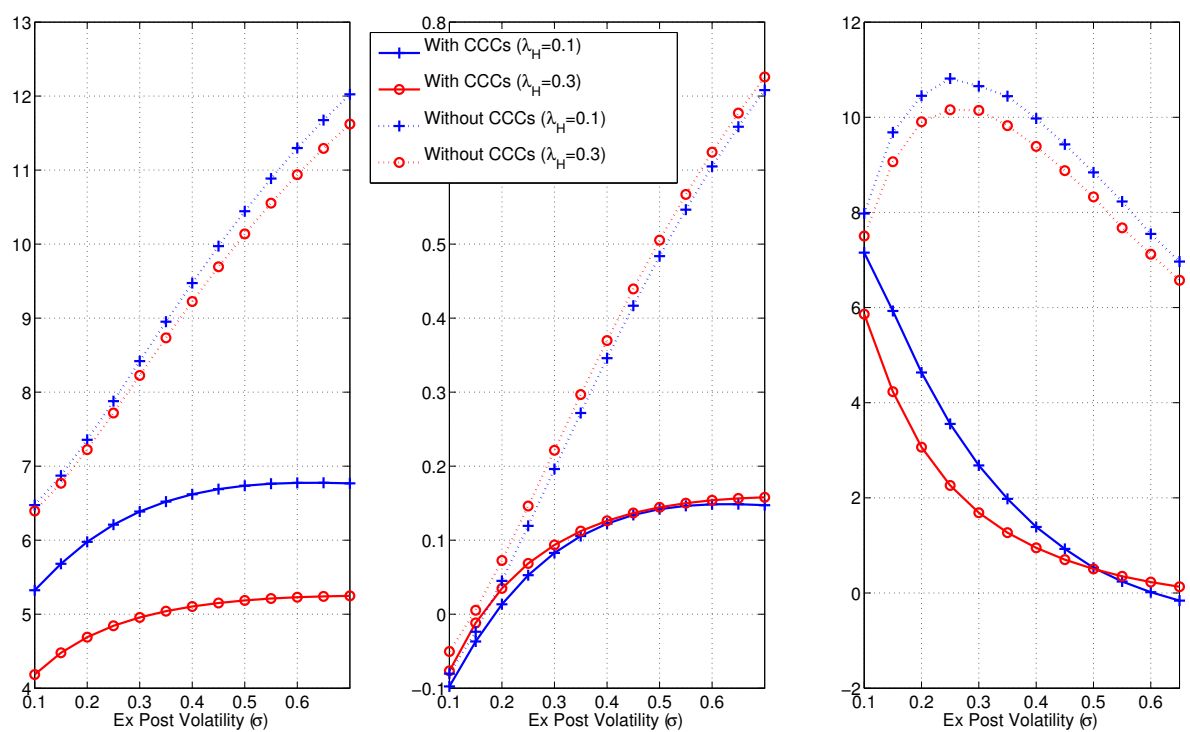

Figure 7: Asset substitution incentive when the decision is taken in a good state of the economy but it immediately switches to a bad condition for different probability of $\lambda_{H}$. The first picture on the left hand side depicts the value of the equity as a function of the ex post volatility $e(\sigma)$; the second picture shows the values of $\frac{e(\sigma)-e(\sigma=0.1)}{e(\sigma=0.1)}$; finally the last picture shows $\partial e(\sigma) / \partial \sigma$, i.e., the derivative of the first picture. 
function of the riskiness of the company. The shape is due to the relation between the probability of touching the lower barrier, and thus conversion of CCC, and the probability of switching to a good state, and thus to face bankruptcy. The non monotonic behaviour of the optimal leverage comes from the trade off for claim holders when the capital structure decision is taken in a bad state of the economy: 1) given that in bad macroeconomic conditions there is no risk of default, claim holders have the incentive to increase the coupons of both debt like instruments to augment the tax benefit; 2) a large optimal coupon leads to an increase of bankruptcy risk and costs if the state of the economy switches to good. In a good state or in a framework without CCC an increase of volatility reduces the leverage (bankruptcy is more likely), in a bad state with CCC we observe the same phenomenon (second effect) but for a large enough volatility the probability of switching to a good state - and therefore of bankruptcy - is so small that the first effect prevails over the second one in the above tradeoff with an incentive to set a high coupon (and debt value) to exploit tax benefit. The combination of these effects explains the leverage shape in Figure 8. A reduction of the viscosity of the bad state, i.e., an increase in $\lambda_{L}$, eliminates this trade off and the optimal leverage turns out to be a decreasing function of volatility.

We conclude our analysis considering the asset substitution phenomenon in a bad state (both capital structure and asset decisions are taken in a bad state). The effect is similar to the one observed when the capital structure is defined in a good state and asset decisions are taken in a bad state, see Figure 7.

\section{Non Countercyclical Contingent Capital}

In this section we compare a CCC to a contingent capital with no asymmetry, i.e., notes like those considered in Barucci and Del Viva [2010]: whatever macroeconomic conditions are, contingent capital certificates are converted as the barrier $x_{H_{0}}^{*}$ and $x_{L_{0}}^{*}$ are touched. The two barriers are decided by equity holders with no role for the regulatory authority, on the effect of equity holders or central authority conversion 


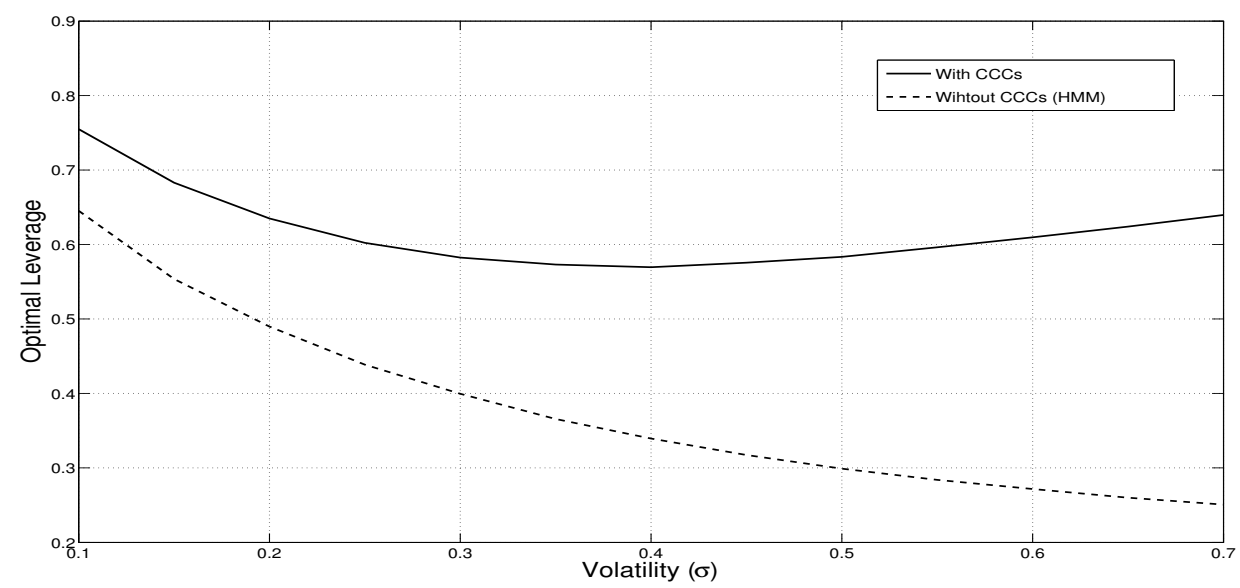

Figure 8: Optimal leverage ratio for different values of volatility when the capital structure is decided in bad macroeconomic conditions. The figure compares the optimal leverage obtained in our model with the results obtained without CCCs, i.e., the standard Hackbarth et al. 2006 model.

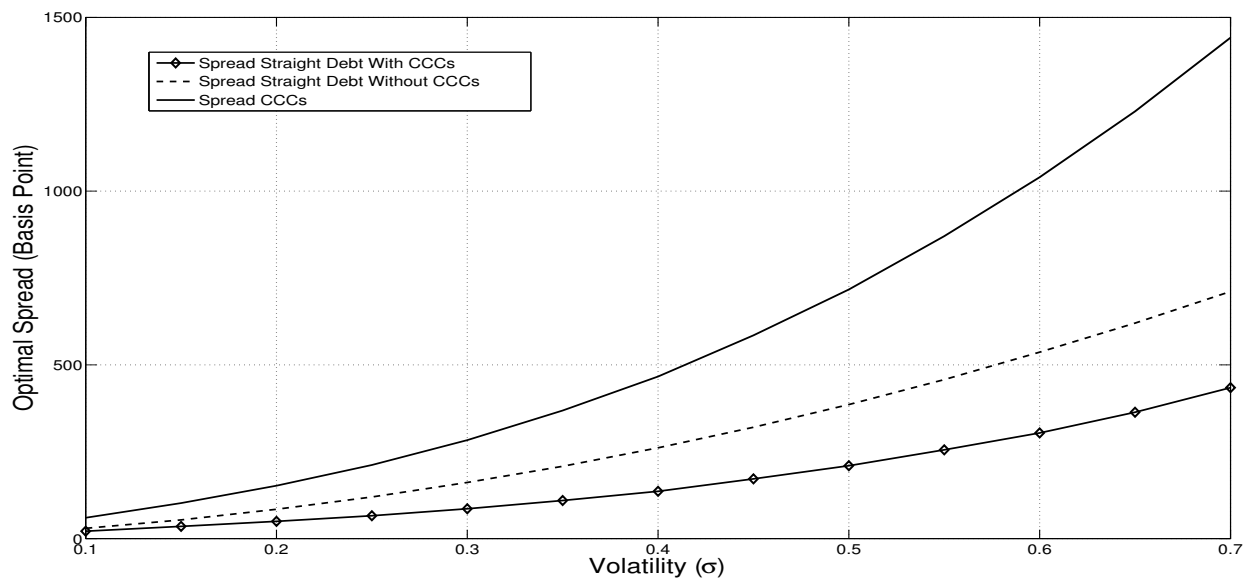

Figure 9: Optimal spreads for different values of volatility when the capital structure is decided in bad macroeconomic conditions. The figure compares the optimal spread obtained in our model with the results obtained without CCCs, i.e., the standard Hackbarth et al. 2006 model. 
decision see Barucci and Del Viva 2010]. In order to remove the countercyclicality feature we have to modify the boundary conditions in (4.6), (4.9) and 4.10). In particular we have to set the following conditions

$$
\begin{aligned}
d_{H_{0}}\left(x_{H_{0}}^{*}\right) & =d_{H_{1}}\left(x_{H_{0}}^{*}\right) \\
C C C_{H_{0}}\left(x_{H_{0}}^{*}\right) & =\theta e_{H_{1}}\left(x_{H_{0}}^{*}\right) \\
v_{H_{0}}\left(x_{H_{0}}^{*}\right) & =v_{H_{1}}\left(x_{H_{0}}^{*}\right) .
\end{aligned}
$$

By these boundary conditions, contingent capital will be converted into equity even if the state of the economy is good, i.e., $H$, and the lower barrier $x_{H_{0}}^{*}$ is touched. Given that default in Period 0 cannot happen we have to fix a conversion barrier even for the good state $H$. The smooth pasting conditions allow us to determine them as $x_{H_{0}}^{*}, x_{L_{0}}^{*}$ such that:

$$
\left\{\begin{array}{c}
e_{H_{0}}^{\prime}\left(x_{H_{0}}^{*}\right)=0 \\
e_{L_{0}}^{\prime}\left(x_{L_{0}}^{*}\right)=0 .
\end{array}\right.
$$

Figure 10 shows the optimal spread in case of a countercyclical and non countercyclical contingent capital. The figure shows that elimination of countercyclicality increases the optimal spread of contingent capital and of straight debt with the exception of straight debt for a small volatility.

In principle the optimal spread is given by the comparison between an expected opportunity cost, i.e., the coupon that we lose in case of bankruptcy, and an expected positive pay-off, i.e., the recovery value at default. For a constant passage probability the higher is this difference the higher is the spread. For low values of volatility, because of the write down risk, the spread of straight debt with CCC is higher than that obtained with non countercyclical CC. As volatility increases, the increase of the coupon of straight debt with CCC is lower than in the absence of the countercyclicality feature. Along with the higher probability of conversion, this explains the higher spread when contingent capital is not countrecyclical. Overall our analysis confirms that conversion of $\mathrm{CC}$ is a risky event: a non countercyclical $\mathrm{CC}$ is much more risky than a CCC and therefore the spread is higher. Also straight debt becomes riskier 

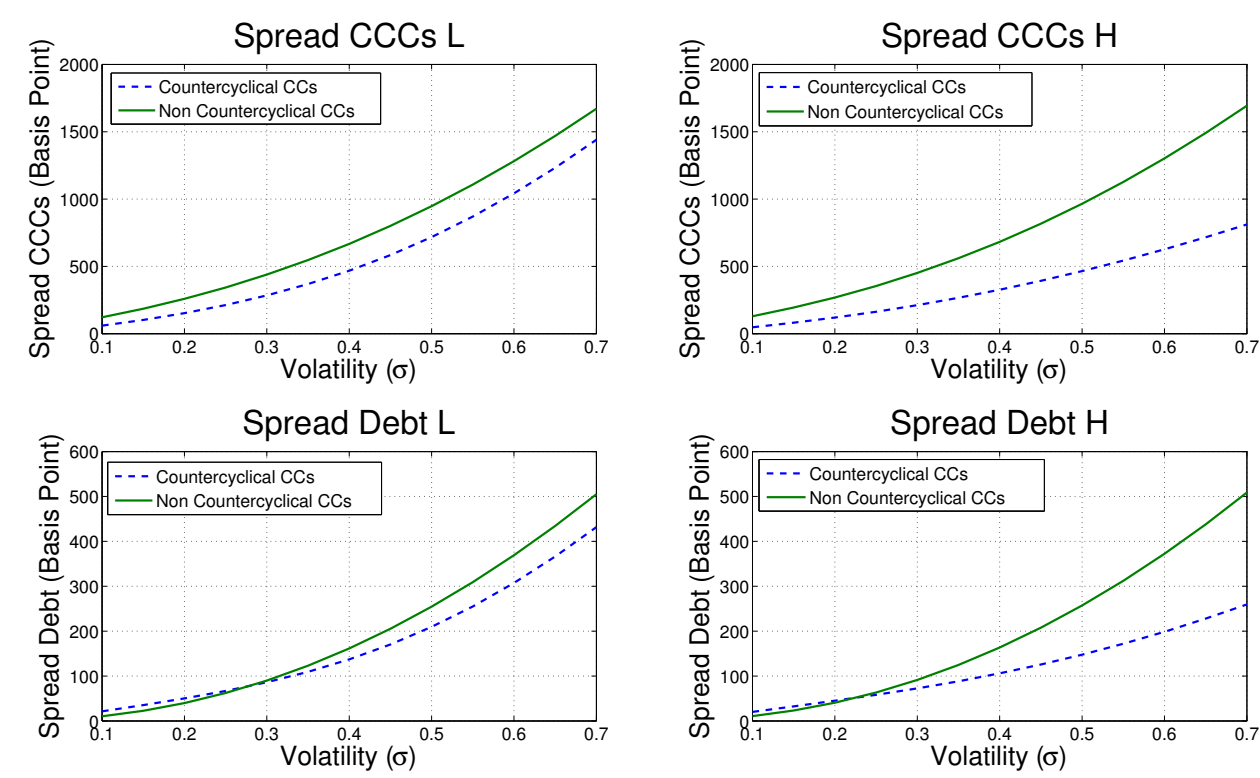

Figure 10: Optimal spread with and without the countercyclicality feature in the bad state (L) and in the good state $(\mathrm{H})$. The conversion barriers for the non countercyclical case are obtained endogenously applying the smooth pasting conditions to equity.

when non countercyclical CC is issued.

In Figure 11 we provide the leverage with contingent capital with and without countercyclicality in the two states of the economy. Eliminating the countercyclicality feature, we observe an increase in the optimal leverage. Indeed, the reduction of bankruptcy costs (non default assumption in state $H$ ) induces to issue more debt and as a consequence the optimal leverage goes up.

As far as the asset substitution incentive is concerned, Figures 12 and 13 show that CCC provides a lower asset substitution incentive than that observed in case of non countercyclical contingent capital, in a bad and in a good state, respectively. The intuition of this result is that the optimal level of straight debt with CCC is lower than the level in the non countercyclical case. A lower value of debt produces a lower incentive to increase the riskiness of the company. As it can be seen from Figure 12 , if the decision regarding the capital structure is taken in a good state of the economy then the countercyclical feature produces a stronger incentive only for a high volatility. 

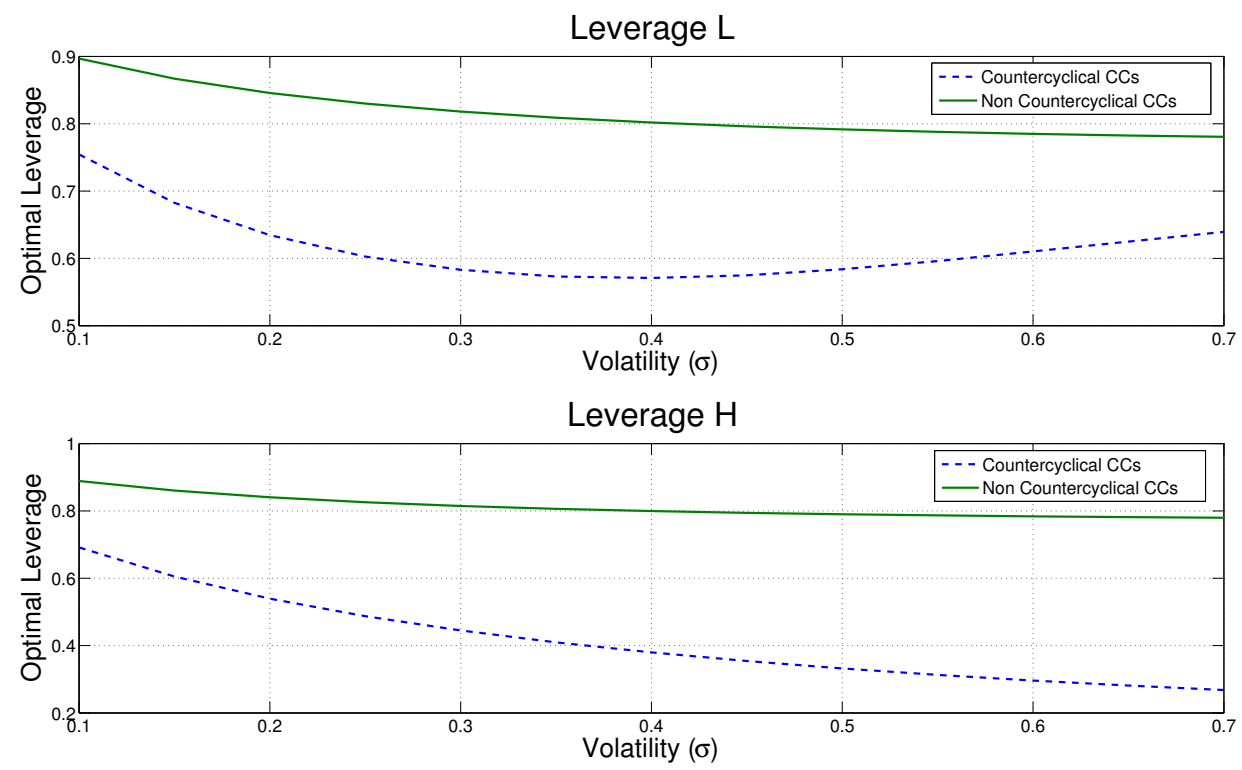

Figure 11: Optimal leverage with and without the countercyclicality feature in the bad state (L) and in the good state $(\mathrm{H})$. The conversion barriers for the non countercyclical case are obtained endogenously applying the smooth pasting conditions to the equity.

This effect is due to the possibility of going bankrupt in a good state of the economy when CCC are issued: given that a high volatility produces a small stopping time, the probability of exploiting the conversion feature vanishes and thus CCC behaves like straight debt reinforcing the asset substitution incentive compared to the non countercyclical counterpart.

We conclude that contingent capital - with and without countercyclicality - produces positive effects in terms of a lower asset substitution incentive compared to the case without CC. The countercyclical feature, reducing the optimal value of debt, reinforces the magnitude of the effect.

\section{Countercyclical Callable Bonds}

In this section we extend the model allowing for dynamic capital structure choices: shareholders are forced by the regulatory authority to restructure the company issuing 

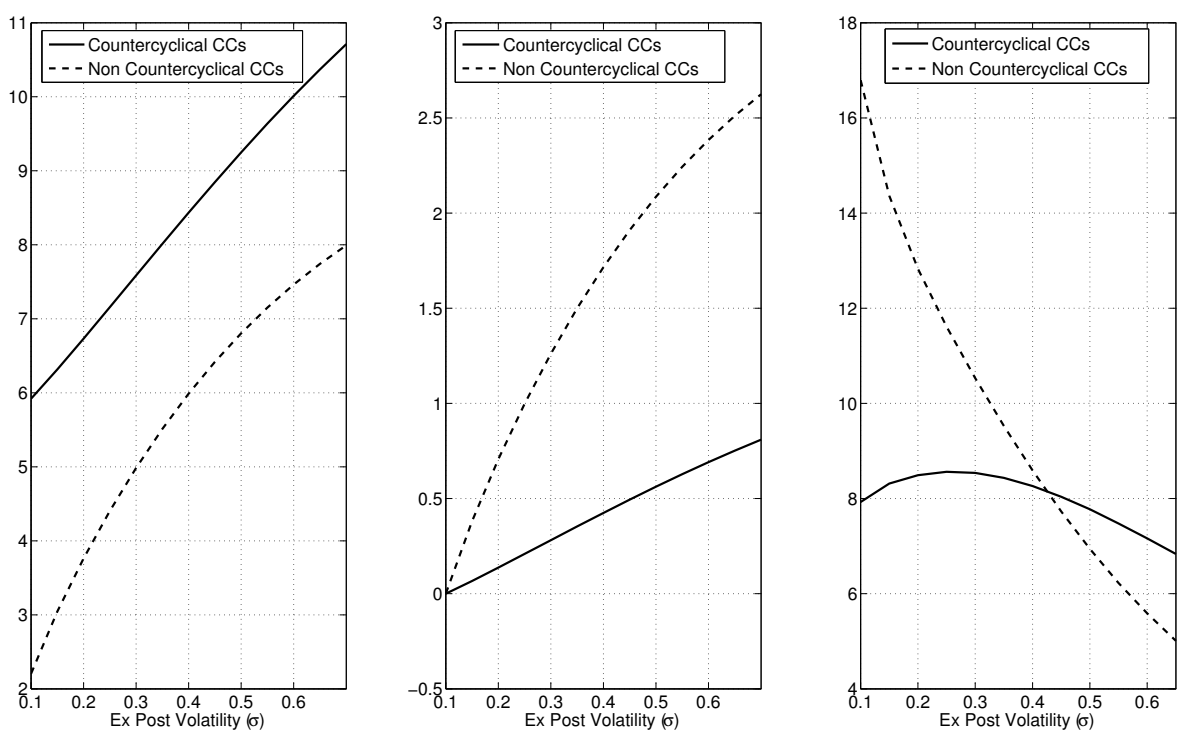

Figure 12: Countercyclical v.s. Non Countercyclical asset substitution incentive in a good state of the economy. The first picture on the left hand side depicts the value of the equity as a function of the ex post volatility $e(\sigma)$; the second picture shows the values of $\frac{e(\sigma)-e(\sigma=0.1)}{e(\sigma=0.1)}$; the last picture shows $\partial e(\sigma) / \partial \sigma$, i.e., the derivative of the first picture. 

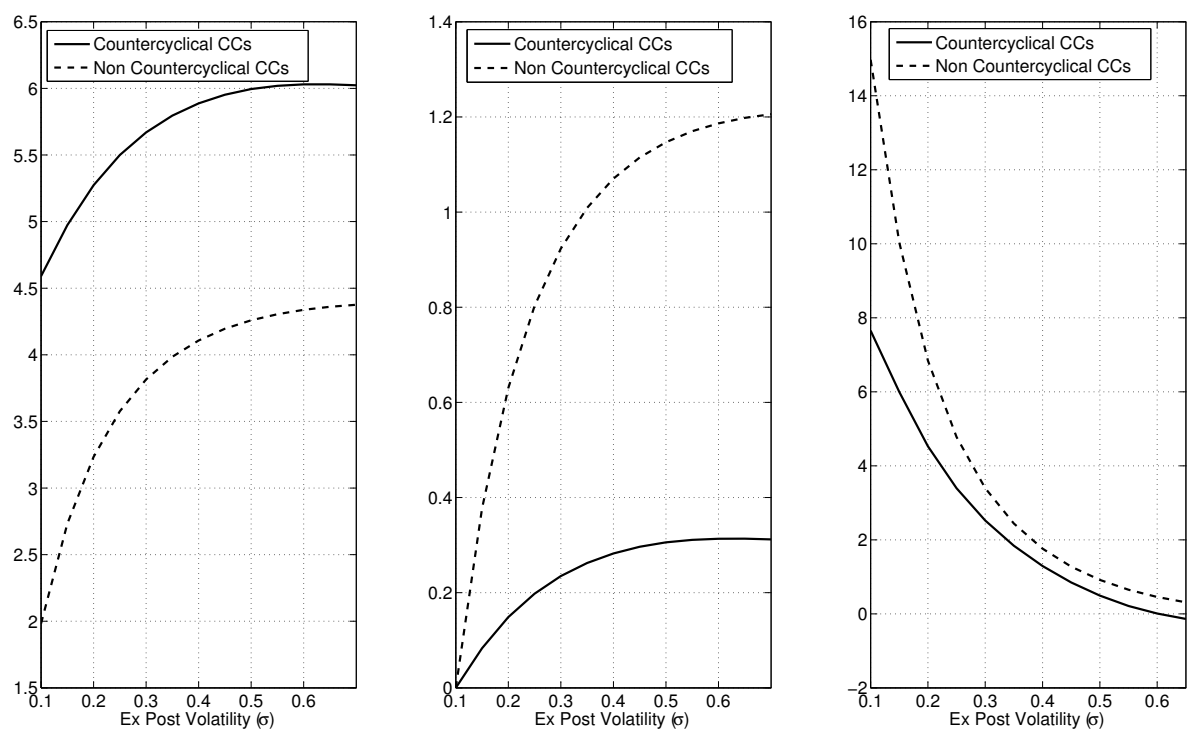

Figure 13: Countercyclical v.s. Non Countercyclical asset substitution incentive in a bad state of the economy. The first picture on the left hand side depicts the value of the equity as a function of the ex post volatility $e(\sigma)$; the second picture shows the values of $\frac{e(\sigma)-e(\sigma=0.1)}{e(\sigma=0.1)}$; the last picture shows $\partial e(\sigma) / \partial \sigma$, i.e., the derivative of the first picture. 
new debt. In order to maintain the countercyclicality feature we assume that the option to restructure, avoiding bankruptcy, can be exercised only in a bad state of the economy and is forced by the regulatory authority when an EBIT barrier is touched in a bad state. In this setting there is no difference between CCC and straight debt, both are called back by the company. Debt looks like a countercyclical callable bond because it is never converted in equity: in a bad state with a poor performance bonds are called back by the bank and other bonds are issued. We can interpret our setting as the possibility for the regulatory authority to force debt restructuring. We refer to this instrument as countercyclical callable bond or dynamic contingent capital.

Our analysis is similar to the one of Goldstein et al. 2001, the main difference is that restructuring is forced by the regulatory authority in a bad state when the performance is not good (and not in a case of a good performance as in the above paper). Indeed, as in the previous sections, if macroeconomic conditions are good and the lower barrier $x_{H}^{*}$ is touched then the bank defaults without debt restructuring. As we have more than two periods, in this section we suppress the subscript 0 and 1 from the barriers and claim value notation, i.e., we use $x_{H}, x_{L}$ instead of $x_{H_{i}}, x_{L_{i}}$. We assume that whenever the EBIT reaches the threshold $x_{L}^{*}$ defined by the regulatory authority during bad states, all the assets are retired at their market value and a new capital structure decision is taken. To facilitate the comparison of this setting with the one analyzed in the previous sections we set $x_{L}^{*}=R_{0} x_{H}^{*}$. The scaling features of our model allow us to use the dynamic framework of Goldstein et al. 2001, Hackbarth et al. 2006, Leland 19982. Linearity of the optimal barriers and of coupons, on the coupons and on the initial EBIT value respectively, implies that the optimal claim values are scaled by the factor $\rho=\frac{x_{i}}{x_{0}}$, where $x_{i}$ is the restructuring barrier $\left(x_{L}^{*}\right)$ and $x_{0}$ is the initial EBIT value. In the present dynamic setting the firm value satisfies the following equation:

\footnotetext{
${ }^{2}$ It can be proved numerically that the conversion/bankruptcy barriers are proportional to straight debt and CCC coupons. Moreover, the optimal coupon obtained is proportional to the initial firm value $x_{0}$.
} 
- if $x_{H}^{*} \leq x \leq x_{L}^{*}$ :

$$
r v_{H}(x)=\mu x v_{H}^{\prime}(x)+\frac{\sigma^{2}}{2} x^{2} v_{H}^{\prime \prime}(x)+\lambda_{H}\left[\frac{x}{x_{0}} v_{L}\left(x_{0}\right)-v_{H}(x)\right]+(1-\tau) x y_{H}+c \tau
$$

- if $x>x_{L}^{*}$ :

$$
\left\{\begin{array}{l}
r v_{L}(x)=\mu x v_{L}^{\prime}(x)+\frac{\sigma^{2}}{2} x^{2} v_{L}^{\prime \prime}(x)+\lambda_{L}\left[v_{H}(x)-v_{L}(x)\right]+(1-\tau) x y_{L}+c \tau \\
r v_{H}(x)=\mu x v_{H}^{\prime}(x)+\frac{\sigma^{2}}{2} x^{2} v_{H}^{\prime \prime}(x)+\lambda_{H}\left[v_{L}(x)-v_{H}(x)\right]+(1-\tau) x y_{H}+c \tau .
\end{array}\right.
$$

The general solutions of the above equations are similar to the non dynamic case where $\rho=x_{L}^{*} / x_{0}$. In particular for the firm value we have:

- if $x_{H}^{*} \leq x \leq x_{L}^{*}$ :

$$
v_{H}(x)=U_{1} x^{\phi_{1}}+U_{2} x^{\phi_{2}}+\frac{\lambda_{H} x v_{L}\left(x_{0}\right)}{x_{0}\left(r+\lambda_{H}-\mu\right)}+\frac{\tau c}{r+\lambda_{H}}+\frac{y_{H} x(1-\tau)}{r+\lambda_{H}-\mu}
$$

- if $x>x_{L}^{*}$ :

$$
\begin{aligned}
v_{L}(x) & =\frac{1}{\lambda_{H}+\lambda_{L}} Z_{1} x^{\xi}-\frac{\lambda_{L}}{\lambda_{H}+\lambda_{L}} J_{1} x^{\gamma}+K_{L} x(1-\tau)+\frac{\tau c}{r} \\
v_{H}(x) & =\frac{1}{\lambda_{H}+\lambda_{L}} Z_{1} x^{\xi}+\frac{\lambda_{H}}{\lambda_{H}+\lambda_{L}} J_{1} x^{\gamma}+K_{H} x(1-\tau)+\frac{\tau c}{r} .
\end{aligned}
$$

The constant parameters $U_{1}, U_{2}, J_{1}$ and $Z_{1}$ are obtained applying the following boundary conditions:

$$
\begin{aligned}
v_{L}\left(x_{L}^{*}\right) & =\rho v_{L}\left(x_{0}\right) \\
v_{H}\left(x_{H}^{*}\right) & =\alpha_{H} A_{H}\left(x_{H}^{*}\right) \\
\lim _{x \uparrow x_{L}^{*}} v_{H}(x) & =\lim _{x \downarrow x_{L}^{*}} v_{H}(x) \\
\lim _{x \uparrow x_{L}^{*}} v_{H}^{\prime}(x) & =\lim _{x \downarrow x_{L}^{*}} v_{H}^{\prime}(x)
\end{aligned}
$$

Similar equations apply for the remaining claims values and are available, together with solutions, from the authors upon request. 


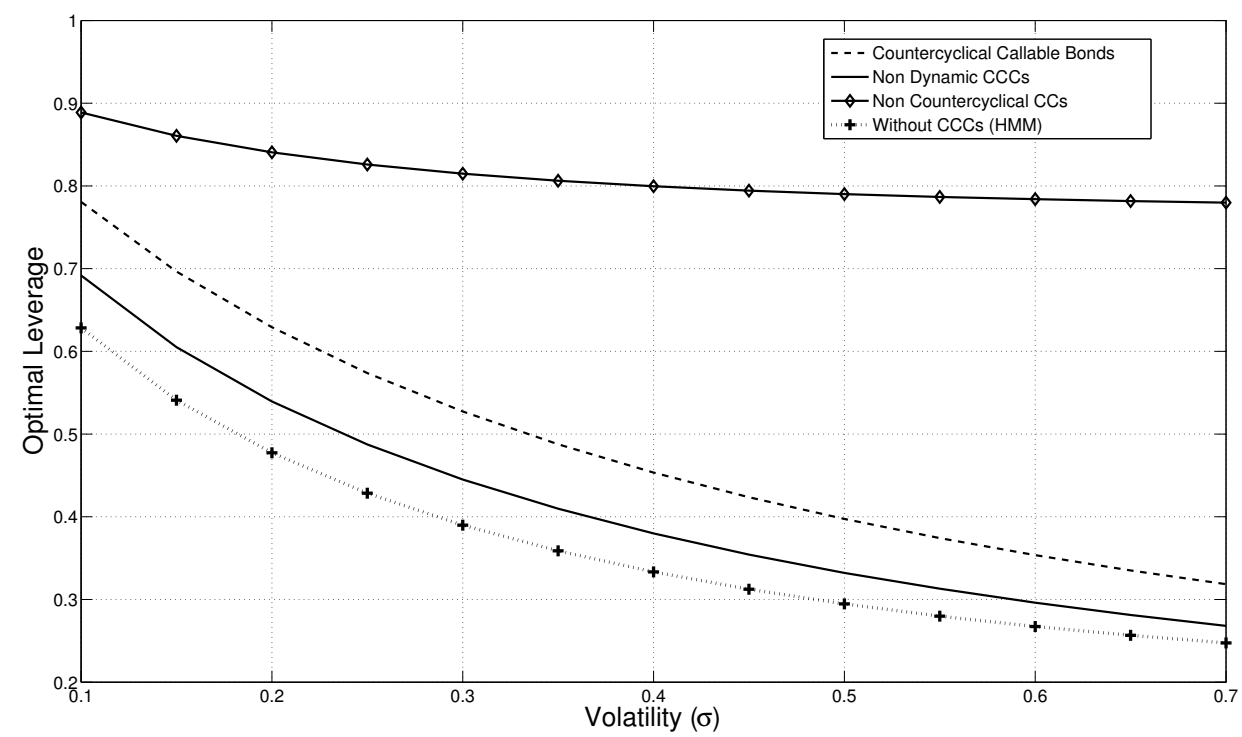

Figure 14: Optimal leverage for different combinations of volatility for the countercyclical callable bond, non countercyclical and countercyclical CC and without CC when macroeconomic conditions are good.

The optimal leverage in the multiperiod dynamic framework for different values of volatility is shown in Figure 14. Allowing for an automatic capital restructuring the leverage becomes larger than the level observed in a standard company and in a company issuing CCC. Instead, the level of leverage with automatic debt restructuring is lower than the level of leverage of a company issuing non countercyclical CC. These results are confirmed when the capital decision is taken in a bad macroeconomic state. Basically the possibility of restructuring the capital structure in a future period - when the operating profit deteriorates - increases the optimal coupons - and the leverage in both states of the economy.

As far as the asset substitution issue is concerned, in Figure 15 we show that countercyclical callable bonds strongly increases the incentive to increase the risk of the bank. The main reason for a higher incentive is an overall higher debt exposition compared to the countercyclical contingent capital as illustrated in Figure 14. 

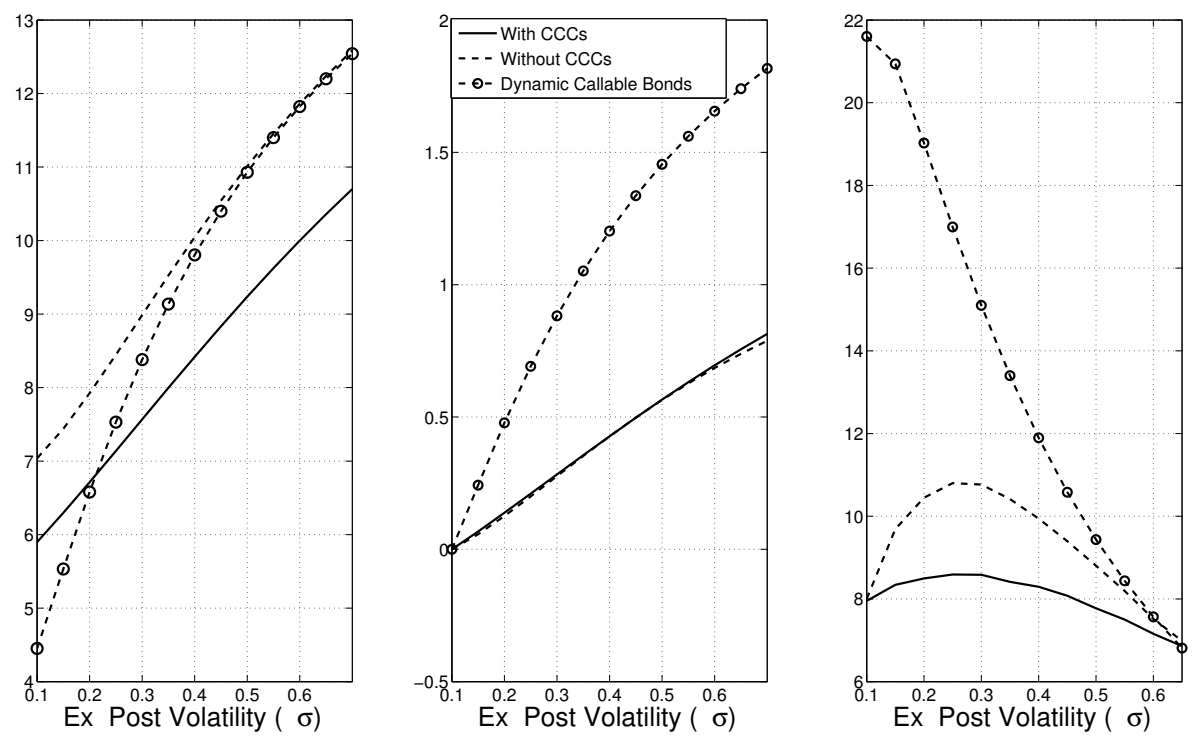

Figure 15: Countercyclical Callable bond v.s. Countercyclical Contingent Capital asset substitution incentive in a good state of the economy. The first picture on the left hand side depicts the value of the equity as a function of the ex post volatility $e(\sigma)$; the second picture shows the values of $\frac{e(\sigma)-e(\sigma=0.1)}{e(\sigma=0.1)}$; the last picture shows $\partial e(\sigma) / \partial \sigma$, i.e., the derivative of the first picture. 


\section{Bankruptcy Costs}

In the end we compare expected bankruptcy costs without contingent capital, with CCC (dynamic and non dynamic case) and with non countercyclical contingent capital, see Figure 16 for the good state of the economy and Figure 17 for the bad state. The analysis shows that only non countercyclical CC allows to reduce bankruptcy costs significantly. This is due to the fact that there is not bankruptcy in Period 0. CCC increases bankruptcy costs in a bad state and has a little effect in a good state. The first result is due to the large exposition taken by the company through a high CCC coupon. Indeed in the bad state of the economy, given the low bankruptcy risk, the coupon of CCC is high. This choice increases the probability of going bankrupt, together with an increase in bankruptcy costs in the bad macroeconomic state and a small reduction in case of a good macroeconomic state. The low probability of leaving the bad state ( $\lambda_{L}=0.15$ in our setting) provides an incentive for this myopic decision (increase the overall debt exposition). Indeed, an increase of $\lambda_{L}$ reduces the optimal coupon for CCC and the associated bankruptcy costs.

As it can be seen from Figure 16 the possibility to restructure the capital structure in the future reduces the bankruptcy costs for low values of volatility. The rationale for this effect lies on the high expected bankruptcy stopping time. Indeed, for a low volatility there is a higher probability of changing state than of going bankrupt. Therefore, there is a high probability to reissue debt and this reduces the optimal bankruptcy barrier and bankruptcy costs. As the volatility increases, the probability of touching the bankruptcy barrier goes up and this eliminates the advantage of a future debt restructuring.

Finally we discuss the effect played by a different conversion rule of $C C$ imposed by the authority (either in equity or in debt). We omit the picture but the numerical analysis shows that if the authority decides to impose an earlier conversion of the CCC (higher $R_{0}$ ) then there is a reduction of bankruptcy costs. As the conversion barrier increases the bank increases the amount of straight debt issued and reduces the 


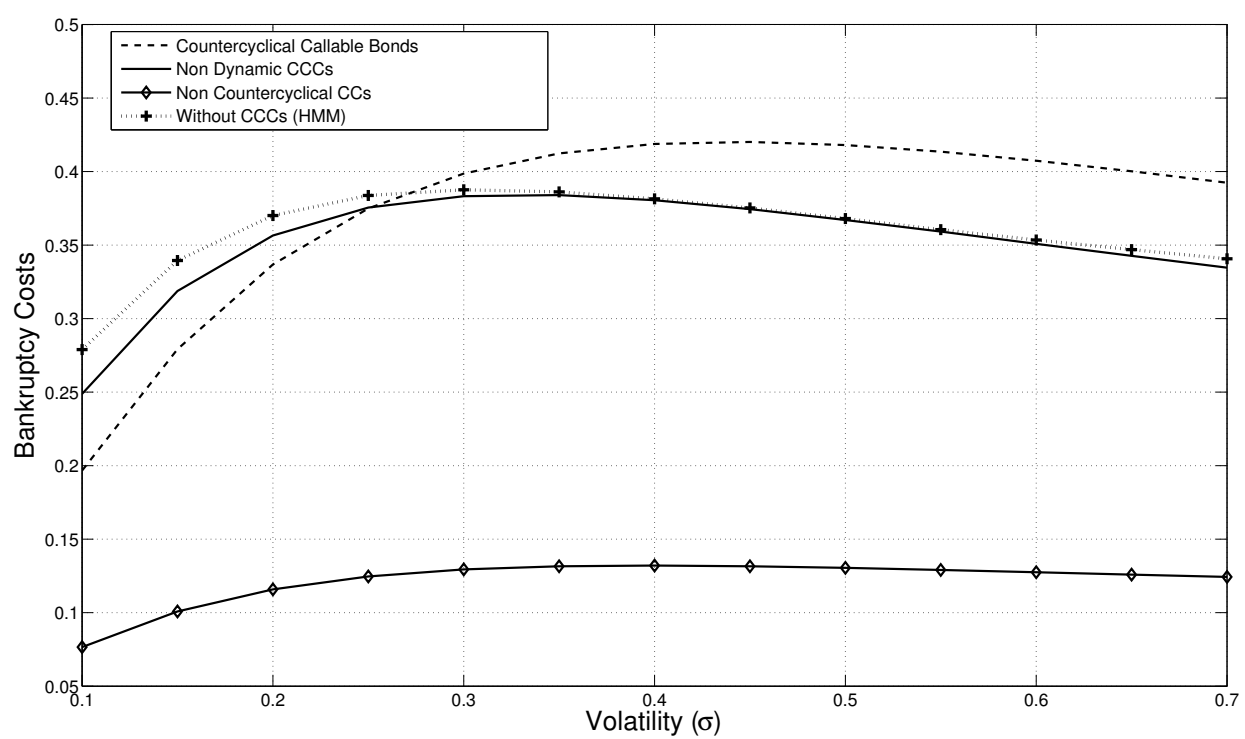

Figure 16: Bankruptcy for different combinations of volatility for the dynamic, countercyclical, non countercyclical CCs and without CCs frameworks when the macroeconomic conditions are good.

amount of CCC. This redistribution of value occurs with a constant level of leverage. The combination of a lower probability of default and a constant overall amount of debt exposition (CCC plus debt) produces the reduction of bankruptcy costs. As far as the asset substitution incentive is concerned, a more stringent conversion rule reduces the incentive of shareholders to switch towards riskier activities. Indeed tighter conversion rules, increasing the conversion barrier, reduces the total debt position and at the same time reduces the incentive for shareholders to increase the risk of the company without incurring in the costs associated with conversion.

\section{Conclusions}

We have analyzed the capital structure of a company issuing countercyclical contingent capital as suggested in the recent regulatory debate, i.e., notes to be converted by a regulatory authority decision in common shares of the bank in case of a bad state for the economy. A dynamic capital structure model with endogenous bankruptcy for a 


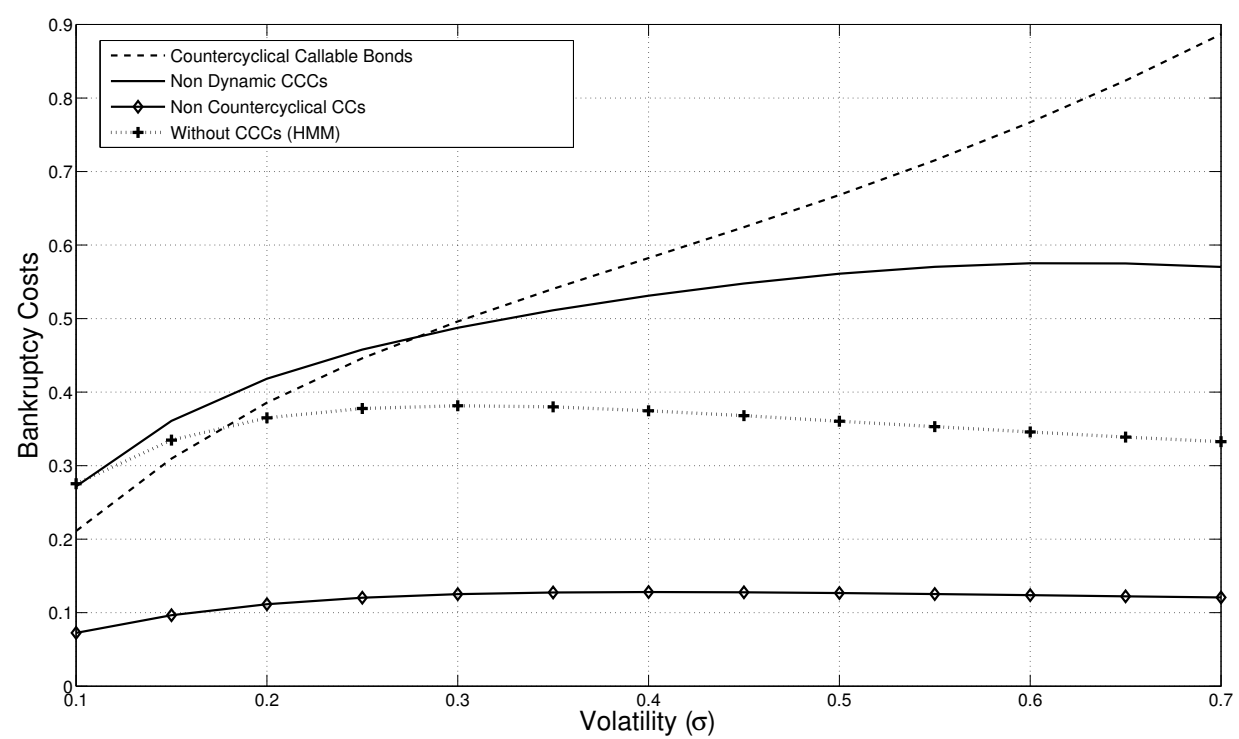

Figure 17: Bankruptcy for different combinations of volatility for the dynamic, countercyclical, non countercyclical CCs and without CCs frameworks when the macroeconomic conditions are bad.

company with equity, straight debt and contingent capital is analyzed. We have shown that the company issuing also CCC becomes slightly more leveraged, large part of risk is absorbed by CCC holders (CCC spread is high and that of straight debt is significantly smaller than in a standard setting), CCC reduces asset substitution incentives while bankruptcy costs are reduced only by issuing non countercyclical contingent capital. Contingent capital to be converted in equity seems to be superior to automatic debt restructuring.

These results provide some interesting insights on the use of countercylical contingent capital for macroprudential regulation. First of all these notes are expensive, they absorb large part of the risk of a riskier company. They are effective in limiting the incentive to adopt risky strategies but they are not effective to reduce bankruptcy costs. To address this issue, non countercylical contingent capital seems to be superior. In order to reduce bankruptcy costs, the conversion of CCC should occur early enough. A debt-equity swap imposed by the regulatory authority through $\mathrm{CC}$ seems to be a more efficient instrument than debt restructuring. 


\section{A Abandonment Value}

Following Hackbarth et al. [2006 the abandonment value is given by

$$
A_{i}(x)=E\left[\int_{0}^{\infty} e^{-r t}(1-\tau) x(t) y(t) d t \mid x_{0}=x, y_{0}=y_{i}\right], \quad i=L, H .
$$

Applying Itô's Lemma we have that $A_{i}(x)$ is given by the solution of the following system of ODE's:

$$
\begin{aligned}
& r A_{L}(x)=\mu x A_{L}^{\prime}(x)+\frac{\sigma^{2}}{2} x^{2} A_{L}^{\prime \prime}(x)+\lambda_{L}\left[A_{H}(x)-A_{L}(x)\right]+(1-\tau) x y_{L} \\
& r A_{H}(x)=\mu x A_{H}^{\prime}(x)+\frac{\sigma^{2}}{2} x^{2} A_{H}^{\prime \prime}(x)+\lambda_{H}\left[A_{L}(x)-A_{H}(x)\right]+(1-\tau) x y_{H}
\end{aligned}
$$

Applying the boundary conditions

$$
\begin{aligned}
& \lim _{x \rightarrow \infty} \frac{A_{i}(x)}{x}<\infty \\
& \lim _{x \rightarrow 0} A_{i}(x)<\infty,
\end{aligned}
$$

$i=L, H$, we obtain the following abandonment values

$$
A_{i}(x)=(1-\tau) K_{i} x, \quad i=L, H
$$

with

$$
\begin{aligned}
K_{H} & =\frac{y_{H}}{r-\mu}-\frac{\lambda_{H}\left(y_{H}-y_{L}\right)}{(r-\mu)\left(r-\mu+\lambda_{L}+\lambda_{H}\right)} \\
K_{L} & =\frac{y_{L}}{r-\mu}+\frac{\lambda_{L}\left(y_{H}-y_{L}\right)}{(r-\mu)\left(r-\mu+\lambda_{L}+\lambda_{H}\right)} .
\end{aligned}
$$




\section{B Claim values in period one}

\section{B.1 Debt Value}

The constants $A_{d}, B_{d}, C_{d}$ and $D_{d}$ have the following expression

$$
\begin{aligned}
A_{d} & =\frac{w d_{1}+\lambda_{L} B_{d} \times\left(x_{L_{1}}^{*}\right)^{\gamma}}{\left(x_{L_{1}}^{*}\right)^{\xi}}, \\
B_{d} & =\frac{\left(w d_{4}+\xi w d_{1}-\beta_{1} w d_{2}\left(x_{L_{1}}^{*} / x_{H_{1}}^{*}\right)^{\beta_{1}}\right) w d_{6}-\left(w d_{3}+w d_{1}-w d_{2}\left(x_{L_{1}}^{*} / x_{H_{1}}^{*}\right)^{\beta_{1}}\right) w d_{8}}{w d_{5} w d_{8}-w d_{6} w d_{7}}, \\
C_{d} & =\frac{w d_{2}-D_{d} \times\left(x_{H_{1}}^{*}\right)^{\beta_{2}}}{\left(x_{H_{1}}^{*}\right)^{\beta_{1}}}, \\
D_{d} & =\frac{\left(w d_{4}+\xi w d_{1}-\beta_{1} w d_{2}\left(x_{L_{1}}^{*} / x_{H_{1}}^{*}\right)^{\beta_{1}}\right) w d_{5}-\left(w d_{3}+w d_{1}-w d_{2}\left(x_{L_{1}}^{*} / x_{H_{1}}^{*}\right)^{\beta_{1}}\right) w d_{7}}{w d_{5} w d_{8}-w d_{6} w d_{7}},
\end{aligned}
$$

and

$$
\begin{array}{ll}
w d_{1}=(1-\tau) \alpha_{L} K_{L} x_{L_{1}}^{*}-\frac{c}{r}, & w d_{2}=\left((1-\tau) \alpha_{H} K_{H}+\frac{w d_{4}}{x_{L_{1}}^{*}}\right) x_{H_{1}}^{*}-\frac{c}{r+\lambda_{H}}, \\
w d_{3}=w d_{4}+\frac{c}{r}-\frac{c}{r+\lambda_{H}}, & w d_{4}=-\lambda_{H} \frac{(1-\tau) \alpha_{L} K_{L} x_{L_{1}}^{*}}{r-\mu+\lambda_{H}}, \\
w d_{5}=\left(\lambda_{L}+\lambda_{H}\right)\left(x_{L_{1}}^{*}\right)^{\gamma}, & w d_{6}=\left(x_{L_{1}}^{*}\right)^{\beta_{2}}-\left(x_{H_{1}}^{*}\right)^{\beta_{2}}\left(\frac{x_{L_{1}}^{*}}{x_{H_{1}}^{*}}\right)^{\beta_{1}}, \\
w d_{7}=\left(\xi \lambda_{L}+\gamma \lambda_{H}\right)\left(x_{L_{1}}^{*}\right)^{\gamma}, & w d_{8}=\beta_{2}\left(x_{L_{1}}^{*}\right)^{\beta_{2}}-\beta_{1}\left(x_{H_{1}}^{*}\right)^{\beta_{2}}\left(\frac{x_{L_{1}}^{*}}{x_{H_{1}}^{*}}\right)^{\beta_{1}} .
\end{array}
$$

\section{B.2 Firm Value}

The constant terms $A_{v}, B_{v}, C_{v}$ and $D_{v}$ satisfy:

$$
\begin{aligned}
A_{v} & =\frac{w v_{1}+\lambda_{L} B_{v} \times\left(x_{L_{1}}^{*}\right)^{\gamma}}{\left(x_{L_{1}}^{*}\right)^{\xi}}, \\
B_{v} & =\frac{\left(w v_{4}+\xi w v_{1}-\beta_{1} w v_{2}\left(x_{L_{1}}^{*} / x_{H_{1}}^{*}\right)^{\beta_{1}}\right) w v_{6}-\left(w v_{3}+w v_{1}-w v_{2}\left(x_{L_{1}}^{*} / x_{H_{1}}^{*}\right)^{\beta_{1}}\right) w v_{8}}{w v_{5} w v_{8}-w v_{6} w v_{7}} \\
C_{v} & =\frac{w v_{2}-D_{v} \times\left(x_{H_{1}}^{*}\right)^{\beta_{2}}}{\left(x_{H_{1}}^{*}\right)^{\beta_{1}}}, \\
D_{v} & =\frac{\left(w v_{4}+\xi w v_{1}-\beta_{1} w v_{2}\left(x_{L_{1}}^{*} / x_{H_{1}}^{*}\right)^{\beta_{1}}\right) w v_{5}-\left(w v_{3}+w v_{1}-w v_{2}\left(x_{L_{1}}^{*} / x_{H_{1}}^{*}\right)^{\beta_{1}}\right) w v_{7}}{w v_{5} w v_{8}-w v_{6} w v_{7}}
\end{aligned}
$$


and

$$
\begin{aligned}
w v_{1} & =(1-\tau)\left(\alpha_{L}-1\right) K_{L} x_{L_{1}}^{*}-\frac{\tau c}{r}, & w v_{2} & =(1-\tau)\left(\alpha_{H} K_{H}-\frac{y_{H}+\lambda_{H} \alpha_{L} K_{L}}{r-\mu+\lambda_{H}}\right) x_{H_{1}}^{*}-\frac{\tau c}{r+\lambda_{H}}, \\
w v_{3} & =w v_{4}+\frac{\lambda_{H}}{\left(r+\lambda_{H}\right)} \frac{\tau c}{r}, & w v_{4} & =(1-\tau)\left(K_{H}-\frac{y_{H}+\lambda_{H} \alpha_{L} K_{L}}{r-\mu+\lambda_{H}}\right) x_{L_{1}}^{*} \\
w v_{5} & =\left(\lambda_{L}+\lambda_{H}\right)\left(x_{L_{1}}^{*}\right)^{\gamma}, & w v_{6} & =\left(x_{L_{1}}^{*}\right)^{\beta_{2}}-\left(x_{H_{1}}^{*}\right)^{\beta_{2}}\left(\frac{x_{L_{1}}^{*}}{x_{H_{1}}^{*}}\right)^{\beta_{1}}, \\
w v_{7} & =\left(\xi \lambda_{L}+\gamma \lambda_{H}\right)\left(x_{L_{1}}^{*}\right)^{\gamma}, & w v_{8} & =\beta_{2}\left(x_{L_{1}}^{*}\right)^{\beta_{2}}-\beta_{1}\left(x_{H_{1}}^{*}\right)^{\beta_{2}}\left(\frac{x_{L_{1}}^{*}}{x_{H_{1}}^{*}}\right)^{\beta_{1}} .
\end{aligned}
$$

\section{B.3 Equity Value}

The constant terms $A_{e}, B_{e}, C_{e}$ and $D_{e}$ satisfy:

$$
\begin{aligned}
A_{e} & =\frac{(1-\tau)\left((\gamma-1) K_{L} x_{L_{1}}^{*}-\gamma \frac{c}{r}\right)}{(\xi-\gamma)\left(x_{L_{1}}^{*}\right)^{\xi}}, \\
B_{e} & =\frac{(1-\tau)\left((\xi-1) K_{L} x_{L_{1}}^{*}-\xi \frac{c}{r}\right)}{\lambda_{L}(\xi-\gamma)\left(x_{L_{1}}^{*}\right)^{\gamma}}, \\
C_{e} & =\frac{(1-\tau)\left(\left(\beta_{2}-1\right) \frac{x_{H_{1}}^{*} y_{H}}{r-\mu+\lambda_{H}}-\beta_{2} \frac{c}{r+\lambda_{H}}\right)}{\left(\beta_{1}-\beta_{2}\right)\left(x_{H_{1}}^{*}\right)^{\beta_{1}}}, \\
D_{e} & =\frac{(1-\tau)\left(\left(\beta_{1}-1\right) \frac{x_{H_{1}}^{*} y_{H}}{r-\mu+\lambda_{H}}-\beta_{1} \frac{c}{r+\lambda_{H}}\right)}{\left(\beta_{2}-\beta_{1}\right)\left(x_{H_{1}}^{*}\right)^{\beta_{2}}},
\end{aligned}
$$

\section{Claim Values Period 0}




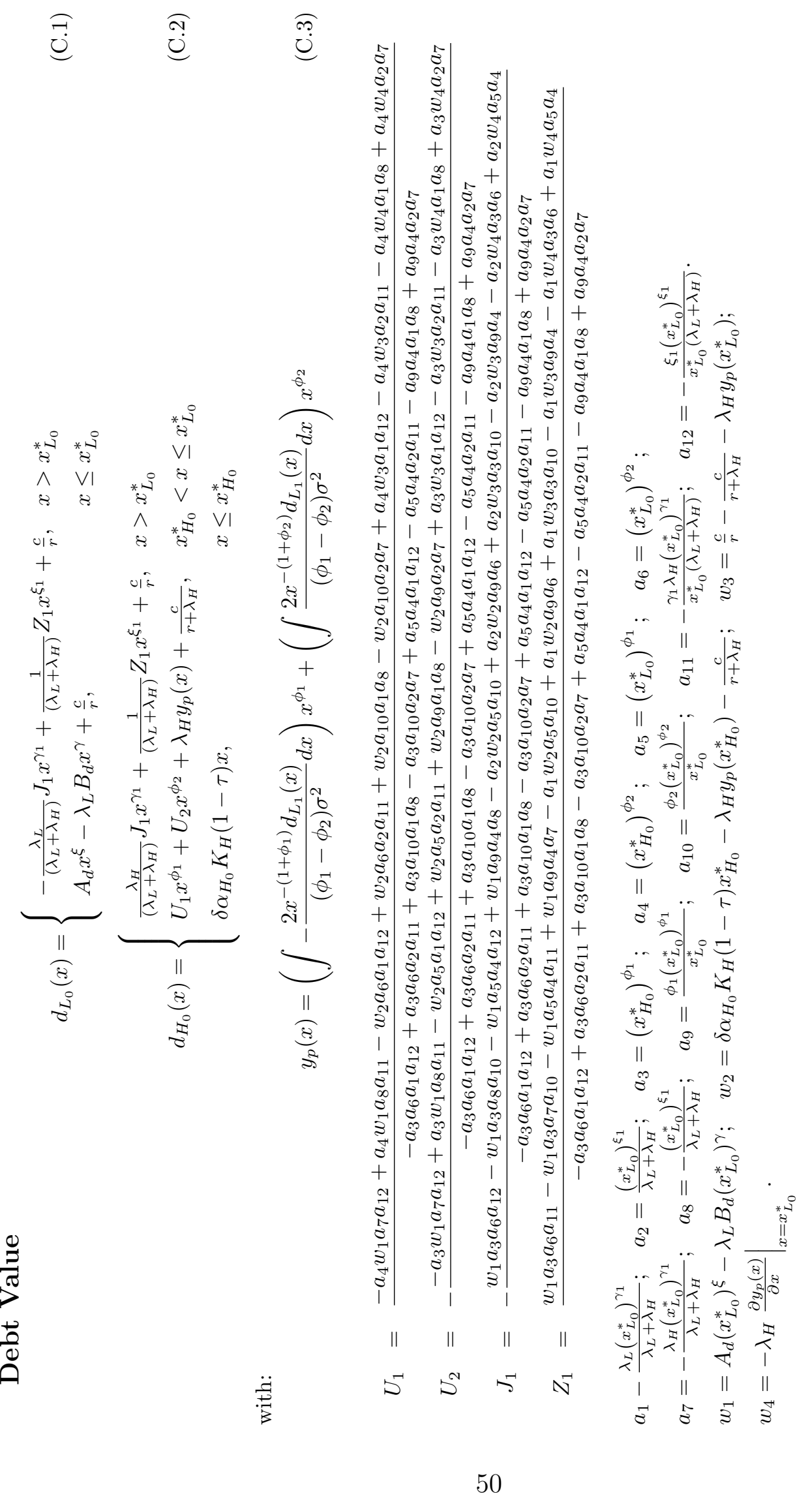




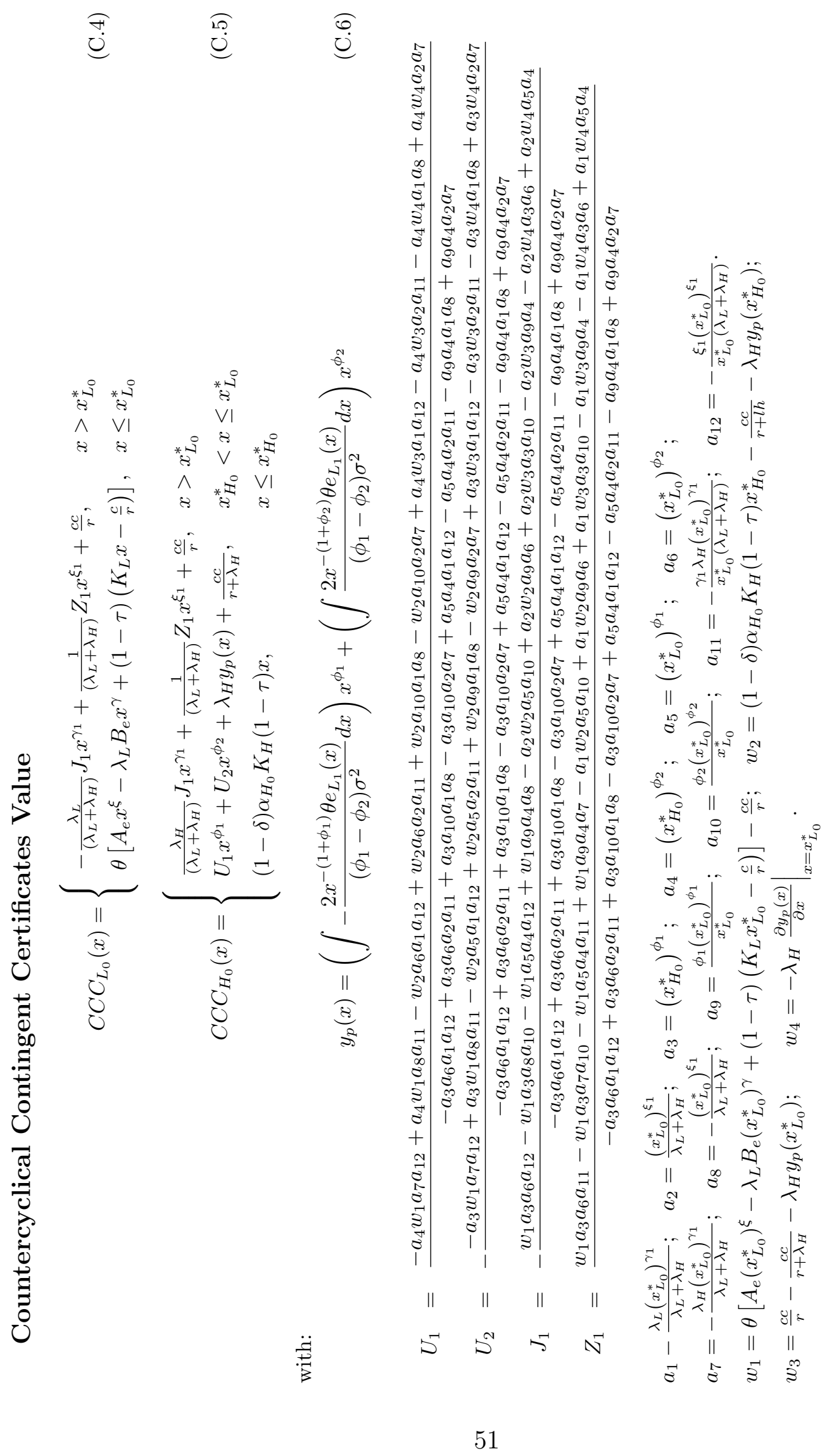




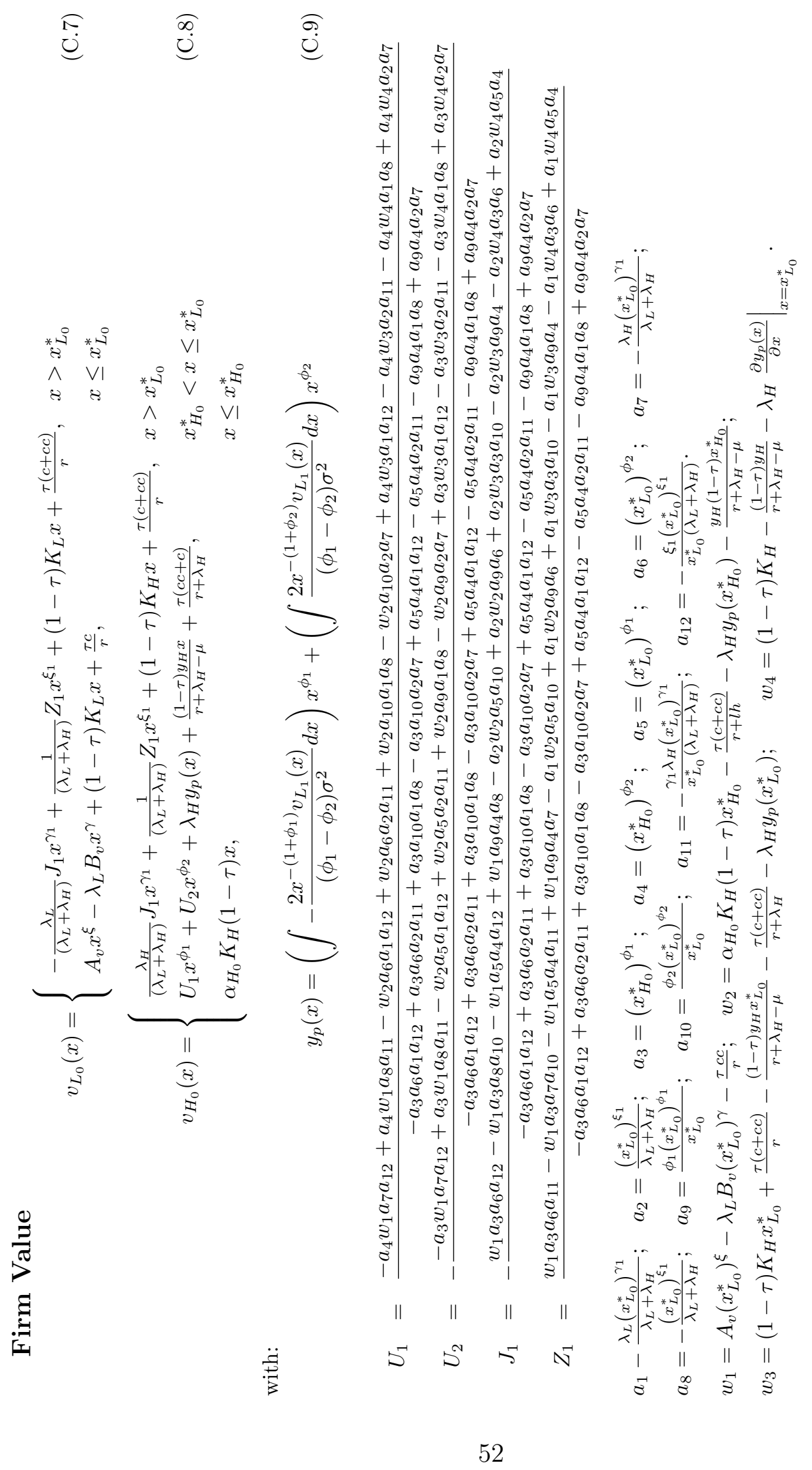




\section{Disentangling the Two ODEs}

$$
\left\{\begin{array}{l}
r v_{L}=\mu x v_{L}^{\prime}+\frac{\sigma^{2}}{2} x^{2} v_{L}^{\prime \prime}+\lambda_{L}\left[v_{H}-v_{L}\right]+(1-\tau) x y_{L}+(c+c c) \tau \\
r v_{H}=\mu x v_{H}^{\prime}+\frac{\sigma^{2}}{2} x^{2} v_{H}^{\prime \prime}+\lambda_{H}\left[v_{L}-v_{H}\right]+(1-\tau) x y_{H}+(c+c c) \tau
\end{array}\right.
$$

From the above system we can obtain a set of two independent ODEs by using $j(x)=v_{H}(x)-v_{L}(x)$ and $z(x)=\lambda_{L} v_{H}(x)+\lambda_{H} v_{L}(x)$ : Substituting in the first equation of D.1 the following $v_{L}(x)=v_{H}(x)-j(x), v_{L}(x)^{\prime}=v_{H}(x)^{\prime}-j(x)^{\prime}$ and $v_{L}(x)^{\prime \prime}=v_{H}(x)^{\prime \prime}-j(x)^{\prime \prime}$ rearranging and looking at the second equation leads to the first independent equation. The derivatives are taken with respect to $x$. The second independent equation is obtained by substituting in the second equation above the following $v_{H}(x)=\frac{1}{\lambda_{L}}\left(z(x)-\lambda_{H} v_{L}(x)\right), v_{H}(x)^{\prime}=\frac{1}{\lambda_{L}}\left(z(x)^{\prime}-\lambda_{H} v_{L}(x)^{\prime}\right)$ and $v_{H}(x)^{\prime \prime}=$ $\frac{1}{\lambda_{L}}\left(z(x)^{\prime \prime}-\lambda_{H} v_{L}(x)^{\prime \prime}\right)$.

\section{E Acknowledgements}

We thank George Pennacchi for comments and suggestions and the participants of seminars at City University and at the ESADE business school. All errors are our responsibility. 


\section{References}

Acharya, Viral, Gujral, Irvind and Shin, Hyun Song (2009) Dividends and Bank Capital in the Financial Crisis of 2007-2009, mimeo.

Admati, Anat and Pfleiderer, Paul (2009) Increased-liability equity: a proposalto improve capital regulation of large finanical institutions, mimeo.

Aggarwal, Raj and Jacques, Kevin T. (2001) The impact of FDICIA and prompt corrective action on bank capital and risk: Estimates using a simultaneous equations model Journal of Banking and Finance 25: 1139-1160.

Albul, Boris, Jaffee M. Dwight and Tchistyi, Alexei (2010) Contingent Convertible Bonds and Capital Structure Decisions, University of Berkeley Coleman Fung Risk Management Research Center working paper nr. 2010-01.

Barucci Emilio and Del Viva Luca (2010), Dynamic Capital Structure and the Contingent Capital Option, mimeo.

Basel Committee on Banking Supervision (2009), Strengthening the resilience of the banking sector, Consultative document, December 2009.

Basel Committee on Banking Supervision (2010a) Countercyclical capital buffer proposal, Consultative document, July 2010.

Basel Committee on Banking Supervision (2010b) Proposal to ensure the loss absorbency of regulatory capital at the point of non-viability, Consultative document, August 2010.

Basel Committee on Banking Supervision (2010c) Group of governors and heads of supervision announces higher global minimum capital standards, Press release, September 2010 . 
Bernanke, Ben (2009) Financial regulation and supervision after teh crisis: the role of the Federal Reserve, Remarks given at the Federal Reserve Bank of Boston 54th economic conference.

Brunnermeier, Markus (2009).Deciphering the Liquidity and Credit Crunch 2007-08, Journal of Economic Perspectives, 23(1): 77-100.

Crouhy, Michel and Galai, Dan. (1991). "A contingent claim analysis of a regulated depository institution." Journal of Banking and Finance 15: 73-90.

De Martino Giuseppe, Libertucci Massimo, Marangoni Mario and Mario Quagliariello (2010), Countercyclical Contingent Capital (CCC): Possible Use and Ideal Design, Questioni di Economia e Finanza, nr. 71.

Duffie, Darrell (2009) Contractual methods for out of court restructuring of systematically important financial institutions, mimeo.

Episcopos, Athanasios (2008) Bank capital regulation in a barrier option framework, Journal of Banking and Finance, 32: 1677-1686.

EU Commission (2010), Public consultation regarding further possible changes to the Capital Requirement Directive ("CRD"), February 2010.

Flannery, Mark (2002) No pain, No gain? Effecting market discipline via "reversed convertible debentures, mimeo.

Flannery, Mark (2009) Stabilizing Large Financial Institutions with Contingent Capital Certificates", mimeo.

Goldstein, Robert, Ju, Nengjiu and Leland, Hayne (2001) An EBIT-Based Model of Dynamic Capital Structure, The Journal of Business, 74, 4: 483-512.

Hackbarth, Dirk, Miao, Jianjun and Morellec, Erwan (2006) Capital Structure, credit risk and macroeconomic conditions, Journal of Financial Economics, 82: 519-550. 
Haldane, Andrew (2009) Rethinking the financial network, mimeo, Bank of England.

Hart, Oliver and Zingales Luigi (2009) A new capital regulation for large financial institutions, mimeo.

Hellwig, Martin Capital Regulation after the Crisis: Business as Usual?, 2010/31, Bonn, Max Planck Institute for Research on Collective Goods.

Kashyap, Anil, Raja, Raghuram and Stein, Jeremy (2008) Rethinking Capital Regulation, mimeo.

Leland, Hayne. (1994). "Corporate Debt Value, Bond Covenant and Optimal Capital Structure." The Journal of Finance, 49, 4: 1213-1252.

Leland, Hayne (1998). "Agency Costs, Risk Management and Capital Structure." The Journal of Finance, LIII, 4: 1213-1243.

McDonald Robert. (2010). "Contingent capital with a dual price trigger." mimeo.

Merton Robert. (1977). "An analytic derivation of the cost of deposit insurance and loan guarantees." Journal of Banking and Finance 1: 3-11.

Pennacchi, George. (2010). "A Structural Model of Contingent Bank Capital." Federal Reserve Bank of Cleveland, working paper nr. 2010-04.

Pennacchi, George, Vermaelen, Theo and Wolff, Christian (2010). Contingent Capital: The Case for COERCs. INSEAD Working Paper 2010/55/FIN.

Raviv, Alon. (2004). "Bank Stability and Market Discipline: Debt-for-Equity Swap versus Subordinated Notes." mimeo.

Squam Lake working group. (2009). "An expendited resolution mechanism for distressed financial firms: regulatory hybrid securities." working paper.

Suresh, Sundaresan and Wang, Zhenya (2010). Design of contingent capital with a stock price trigger for mandatory conversion. Working Paper Columbia University. 